Portland State University

PDXScholar

Public Administration Dissertations and Final

Research Papers

Public Administration

$11-2017$

\title{
Employee Engagement and Marginalized Populations
}

Brenna Miaira Kutch

Portland State University, brennak@pdx.edu

Follow this and additional works at: https://pdxscholar.library.pdx.edu/pubadmin_theses

Part of the Public Administration Commons

Let us know how access to this document benefits you.

Recommended Citation

Kutch, Brenna Miaira, "Employee Engagement and Marginalized Populations" (2017). Public Administration Dissertations and Final Research Papers. 2.

https://pdxscholar.library.pdx.edu/pubadmin_theses/2

This Paper is brought to you for free and open access. It has been accepted for inclusion in Public Administration Dissertations and Final Research Papers by an authorized administrator of PDXScholar. Please contact us if we can make this document more accessible: pdxscholar@pdx.edu. 


\section{EMPLOYEE ENGAGEMENT}
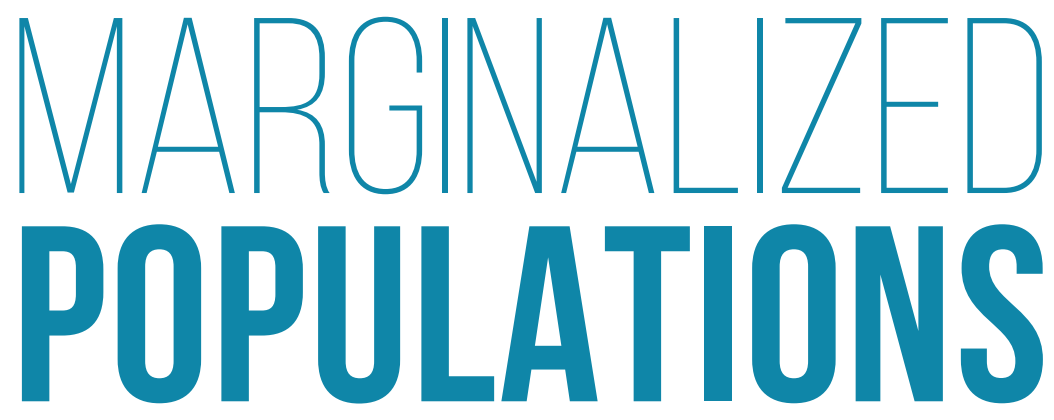

BRENNA MIAIRA KUTCH

PORTLAND STATE UNIVERSITY

NOVEMBER 2017 


\section{INDEX}

\section{EMPLOYEE ENGAGEMENT}

AND MARGINALIZED POPULATIONS: RESEARCH FINDINES AND APPLIGATIONS FOR PORTLAND STATE UNIVERSITV

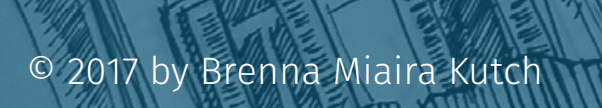

711.1.

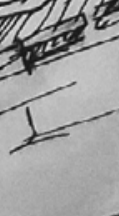




\section{INTRODUCTION}

Portland State University (PSU) is strongly focused on equity and inclusion as evidenced by its strategic priorities, active Office of Global Diversity and Inclusion (OGDI), and many employees and students who care about inclusion and social justice. There is, however, less focus on the employee experience. With nearly 4,000 staff, faculty, ad ministrators, and student workers, PSU runs on the people passionate about serving its mission, but depending on the area of the university in which one is employed, experiences can range from supportive and trusting to micromanaging and disrespectful.

This report examines the employee experience, or employee engagement, at PSU from multiple campus perspectives, and will focus on the expeniences of those in fined as those voices often or historically excluded from the mainstream or "privileged" aspects of PSU, Portland, and society in generat, such as people with disabilities, women, people of color or ethnic minorities, members the LGBTQ community older employees, and political/religious minorities. The Gallup 012 engagement survey was conducted in 2015 and 2016 with a subset of PSU employees that specifically broke participants up into five groups: gender, race/ethnicity, LGBTQ status, and years of service at PSU.

The following report will discuss employee engagement in general, for public employees, and for marginalized populations; provide analysis of how PSU engagement is affected by MP status; examine the contributors and inhibitors of engagement at PSU; and provide recommendations for improving general PSU employee engagement, and particularly engagement among those marginalized groups.

\section{WHAT IS ENGAGEMENT}

1. Importance
a. Performance
b. Happier customers
c. Lower turnover
d. More commitment
e. Innovation
f. Financial benefits
2. Public Sector . Purpose and Public Service Motivation b. Customer Impact = Citizen Impact c. Leadership and the Political Climate

3. Marginalized Populations a. Negative Workplace Impacts b. External Factors c. Privilege and Power in Engagement 


\section{CHAPTER 1 - WHAT IS ENGAGEMENT?}

The effects that employee perceptions and environments have on performance have been studied since the 1930's, and continue to evolve. While the phrasing has changed from satisfaction to engagement over the decades, there has always been a strong correlation between engaged employees and many positive organizational effects.

There are many definitions of "employee engagement" that can help understand how to foster it. These range from the more clinical Jones and Harter definition of a positive, fulfiling, work-related state of mind that is characterized by vigor, dedication, and absorption," to Jacob Morgan ' $\mathrm{s}^{3}$ more philosophical one, "Do you show up to work every day with the intention of helping others succeed?" Rainey and Bakker separate "satisfaction" and "engagement" by the addition of vigor to engagement, where employees demonstrate high-arousal positive states, such as excitement, energy, and enthusiasm. Regardess of which of the many ways to thimk about engagement, one thing is clear. it is focused on the the them with an environment that is caring, supportive, that they enjoy, and from which they get fulfillment.

\section{Importance}

b. Happier customers

The effects of engagement continue to be a focus of many organizational and psychological studies, as it is a synergistic relationship between the organization and its enployees. While the human-side of the engagement question may focus on the employee experience, there are well-documented reasons to foster engagement that are beneficial for the organization and those it serves. Below are a few of those benefits.

\section{a. Performance}

Organizations with engaged employees continually show that employees have higher levels of performance and productivity ${ }^{5}$, give more discretionary effort, and lead to greater organizational performance. There are many contributing factors to this, such as lower sick leaves, the focus on work playing to employees' strengths $5^{65,66}$, and the fact that engaged employees invest more mental, physical and emotional resources to their work. When compared to their non-engaged coworkers, engaged employees not only perform better, but are more willing to help their zenship $p^{4}$. Performance at its core is also affected by many other factors listed below, such as innovation, retention, commitment, and more.

more likely to understand their customers and their er customer satisfactions. Other studies show relationships between employee engagement, customer satisfaction, and the organization's financial benefit?

\section{"THERE IS NO STUDENT SUCCESS WITHOUT EMPLOYEE SUCCESS" \\ KIRK KELLY, PSU INFORMATION TECHNOLOGY}

\section{c. Lower turnover}

Turnover is costly; in fact, most estimates of turnover costs ange from one half to five times the employee's annua salary $y^{2}$, which adds up, especially for large public organitions. Not only does it demand many time and moneta but it is disruptive to exploration will foster more innovation that will breed more engagement. Inovation and creativty are the key to needs ${ }^{5}$, provide higher quality of service, and cause high- gaged employees have higher retention, thus decreasin the negative effects of turnover, including lost time, money, productivity, morale, and mores

d. More commitment

Organizational citizenship, defined as a person's voluntary commitment outside of their assigned tasks, is higher in engaged employees ${ }^{6,4}$ this not only reduces the negative effects of turnover, but reaps the positive benefits of commitment and discretionary effort to the organization "Fully engaged" public sector employees are more likely to stay in their current jobs, feel they can make a difference, recommend their workplace to others, and report being "very satisfied" in their jobs

e. Innovation

Engaged employees are more innovative and creative This, in turn, is a two-way street; organizations that provide an environment that embraces change, failure, an business transformation, especially in a world constantly tion and thought diversity are essential when dealing with complex problems?

f. Financial benefits

Investing in employees has a tangible and significant positive financial impact to the organization ${ }^{3}$ As more employees "have the right materials and equipment to do their work, are in jobs that best fit their talents, feel recognized

and cared about, they are more likely to perform in ways that complement the financial goals of the organization ${ }^{2}$ Organizations that are more financially successful are more likely to invest the right materials and equipment in their employees and hire more employees, which provides latitude for specialization in the jobs employees enjoy and best fit their talents. However, in a negative financial situation, organizations are more likely to cut back on the number of employees and the equipment provided, further increasing the negative working environment? 2 . Professional development funding is often an easy target for budget cuts that negatively effects both the organizaiton and its employees as people.

\section{Public Sector}

Many engagement studies are sector-agnostic, and muc of the publically avallable data is from private organizations. White the nuances of engagement in the public sector (specifically higher education) are less popular, there is still a lot on information out there, and some things to

a. Purpose and Public Service Motivation

One of the greatest motivators of engagement is purpose ${ }^{10}$. Fortunately, in the public sector, the sense of purpose is often easy for employees to understand. Public sector employees cited "Serving the public with integrity" as their most distinguishing engagement factor?.

In fact, there is a specific term for the "general altruistic motivation to serve the interests of a community of people, a state, a nation or humanity" - Public Service Motivation (PSM). PSM "offers the motive to use all the available
"ENGAGED EMPLOYEES ARE THOSE WHO ARE DOING THE BEST THAT THEY CAN EVERY DAY, SHOWING UP AND ABLE TO CONTRIBUTE." ELLEN WEEKS, PSU INFORMATION TECHNOLOGY sis"s" and dedication for the public good on a daily ba政 organizational stressors because of their commitment to serving others. PSM can be harnessed as a motivator and can increase engagement by giving employees opportunities to work with those they serve and by drawing connections between their work and helping others. However, it should not be exploited; if job demands are high but resources are low, employees will suffer burnout and a loss of psychological resources, resulting in lower PSM and dis-

b. Customer impact = citizen impact

While increased customer impact can equal greater fimancial gains in the private sector the effects are slightly different for nonprofit or public organizations. In the pub- 
lic sector, "customers" are actually citizens of whateve city, state, or federal district is funding the organization dents and faculty who are dedicating their lives to education. Employees with high PSM and dedication to serving others will have higher engagement and provide a better experience for their constituents.

c. Leadership and the political climate

Leadership in the public sector can have levels of complication that is not present in the private sector, such as elected officials. Public sector leadership has the opportunity to be more change-focused, people-oriented, and transformational"; however, some research shows that public sector leadership tends to be generally poorer than in the private sector ${ }^{12}$. Other barriers to public sector engagement include constant attacks on government by the public, frequently changing political leadership, bureaucratic constraints to decision-making, multiple externa stakeholders with influence, limited finances, and th unded by the public and the necessary transparency $y^{13}$.

\section{"HOW WOULD YOU ENGAGE WITH YOUR COWORKERS IF YOU FELT OSTRACIZED AND LEFT OUT? \\ DR. CARMEN SUAREZ, PSU DIVERSITY \& INCLUSION}

\section{Engagement and Marginalized Populations}

While employee engagement sounds like it may be straightforward focal point to improve organizational performance and employee well-being, there are unfortunately many obstacles that marginalized populations face that may not be well understood by those in the majority or positions of privilege. While research about the overlap between engagement and being part of a marginalized group does exist, it is scant. However, there is a growing MPs face at work and the effects that it has, which can be easily viewed through the lens of engagement.
There are sadly many examples of the negative impacts that being a marginalized population: they have less support from different-race coworkers and supervisors'; are often ignored more by supervisors ${ }^{14}$, face lower engagement which leads to higher absenteeism or turnover $r^{1 / 4}$ (which can also unfortunately lead to increased bias in looked, and undervalued'; of anxiety and isolation ${ }^{17}$; feel pressure to hide their true selves or face being ostracized, threatened, or discriminated against'; ;ive with only-ness and lack representation or others who understand their situation $n^{16,9}$; experence decreased creative energy and collaboration", and feel dissimilar from others which causes exclusion from important networks that can impact job information and performance ${ }^{20}$. One very common complaint of marginalized populations in the workplace is that they must do more to prove they are "as good" as employees who are part of the majorty, which affects every aspect of employment, from resumes to performance reviews to promotions. For example, the success of women and people for molos is ond whitrib the more to luck, whereas success homer, are more often attributed to lack of skilt where-

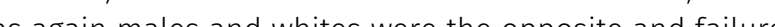
a a atributed to bad luck from extenal causes".

\section{b. External factors}

The above issues alone are hard enough for individuals in the workplace; unfortunately, there are also external factors making it even more difficult. The political climate for a lot of marginalized populations is under constant Oregon, Portland, and PSU now have some strong protections for marginalized groups, including expanded rights for women, people of color, and queer and transgender employees, those in other states and still many in Port-r land face higher chance of violence, being fired for their protected class status, being denied healthcare, and more. Some protections are new enough that many remember a day without them, and many MPs still face the lasting effects of a history of racism, sexism, ableism, homophobia, and more. The recency of some of the basic rights that many have had for centuries is alarming and can help to understand the very slow shift in social acceptance. For or has been a law in Oregon law since 1976 , there are still a lot of ways in unich pay gaps are still perpetuated in hiring and employment practices. Discrimination in hiring varies widely depending status (e.g. race, gender, sexual orientation, disability staus, gender identity, or pregnancy) but there are still very few women, people of color, or LGBTO folks in positions of power. Appendix A summarizes some of the civil rights aws in Oreson and in the United States with a focus on on employment and education, which can help understand just how recently many people have been "given" the right to be treated equally. This can help understand the glacial pace of social change, acceptance, and workplace climate for these populations.

While this report does not focus specifically on these very reat socioculturat issues, we must acknowledge that marginalized populations face many varying stressors that those who are part of majority groups do not. These added stressors in both their professional and personal lives affect the amount of physical, mental, and emotional energy available for work. Additionally, many MPs have faced discrimination in the workplace for years and as such have seen impacts in career growth and disproport entation in lower wage jobs and poverty.

\section{Crivilege and power in engagement}

One more thing to consider about engagement and marginalized populations is who is defining and owning "enyent efforts have typically been measured and lead by the majority people in power, however, . adership must understand it is not a formula for every one Those with less privilege (be it earned, eg degree, or unearned, eg ableness or race) often have less power or control over their situation, and therefore their engagement can be affected more by these uncontrollable attributes. Higher or lower privilege and power can influence how available resources are (or even just the perception of availability) and how demanding a job or task is. Someone with more privilege/power in a particular job/situation may find it more engaging than one with less. Engagement is therefore comprised not only of meaningful work, but of privilege and organizational justice

It is clear that bias in the workplace, be it intentional or unintentional, has very real effects on employees who are part of minority or marginalized groups. The negative effects of discrimination and bias can range, but it is reasonable to assume that loneliness, ostracization, lack of respect, unfairness, and less opportunity for advancement for all very real contributors to decreased engagement for these employees. The rest of this report will focus on recommendations for improving engagement overall, but with particular focus on marginalized employees.
"I frequently encounter people who advocate for equity and diversity and inclusion saying something or acting in a way that is exclusionary to groups that they don't pay attention to; people who are gung ho about racial equity can make a disparaging comment about conservatives, for example, not even being aware of what they are saying. We have to be very self-reflective of ourselvs." Dr. Masami Nishishiba, PSU Center for Public Service 
"IF WE CARE ABOUT PEOPLE,

THAT MEANS ALL PEOPLE. WE

SHOULD HAVE AN INCLUSIVE

ENVIRONMENT WHERE EVERYBODY

FEELS WELCOME, INCLUDED, AND

ENGAGED."

KIRK KELLY, PSU INFORMATION TECHNOLOGY

\section{PSU SURVEY DATA}

1. Statistical Analysis

2. Trends

a. Gender

b. LGBTQ status

c. Race

d. Years of service 


\section{PSU SURVEY DATA}

The Gallup Q12 survey was sent out to a subset of PSU staff for two years in a row. The survey, comprised of 12 questions as the name suggests, is one of the most popular engagement surveys. Gallup began the survey in the 1990s and has millions of datapoints over the years and across organizations. The questions are:

Do you know what is expected of you at work?

Do you have the materials and equipment to do your work right?

"At work, do you have the opportunity to do what you do best every day?

In the last seven days, have you received recognition or praise for doing good work?

"Does your supervisor, or someone at work, seem to care about you as a person?

Is there someone at work who encourages your development?

At work, do your opinions seem to count?

Does the mission/purpose of your company make you feel your job is important?

Are your associates (fellow employees) committed to doing quality work?

Do you have a best friend at work?

In the last six months, has someone at work talked to you about your progress?

Along with the actual Q12 questions, PSU also gathered demographic data for race, gender, LGBTQ status, and years working at PSU. The following graphs focus on the 2016 scores.

\section{Statistical Analysis}

Unfortunately, in order to do a full analysis to assess significant differences between data sets for each of the demographics, the full set of data must be purchased. Some groups had too few participants to be included in the data
Thus, the data must be taken with a grain of salt, especially in terms of comparing the different ethnicities.

Despite the data limitations, we are still able to draw valuable insights. The answers can also help to understand what questions are not being asked or what future research could possibly focus on, e.g. why are certain groups of color feeling so much less invested in

In the future, being able to run a full analysis would be very helpful for understanding the actual differences, bu requires investing in the added cost of data. A baseline has been established, and the survey was just completed for the third year in a row. This means psu can start not drawing cons specifc areas of low scores, but can stat rise in corretated scores (es professionat development a fforts and "Develo of the small sample sizes (for example, some ethnicities of the small sa rate overview when compared to the larger counterparts (e.g. in $2016,74 \%$ of the 308 respondents were white). Expanding the survey to more employees AND increasing the number of non-white employees would increase the reliability and accuracy of the analysis.

Below are graphs depicting the averages for each group; ncluded for each demographic comparison is an overview of the largest differences between groups for each of the populations (the tables in each section below)

\section{Trends}

Below are graphs visualizing the overall averages for each population by each of the 12 Gallup questions (along with ed data AND small sample sizes, there is a likely chance of poputan Bexplating the results to the rest of the PSU a 13th, asking overall satisfaction). Again, due to the limit-

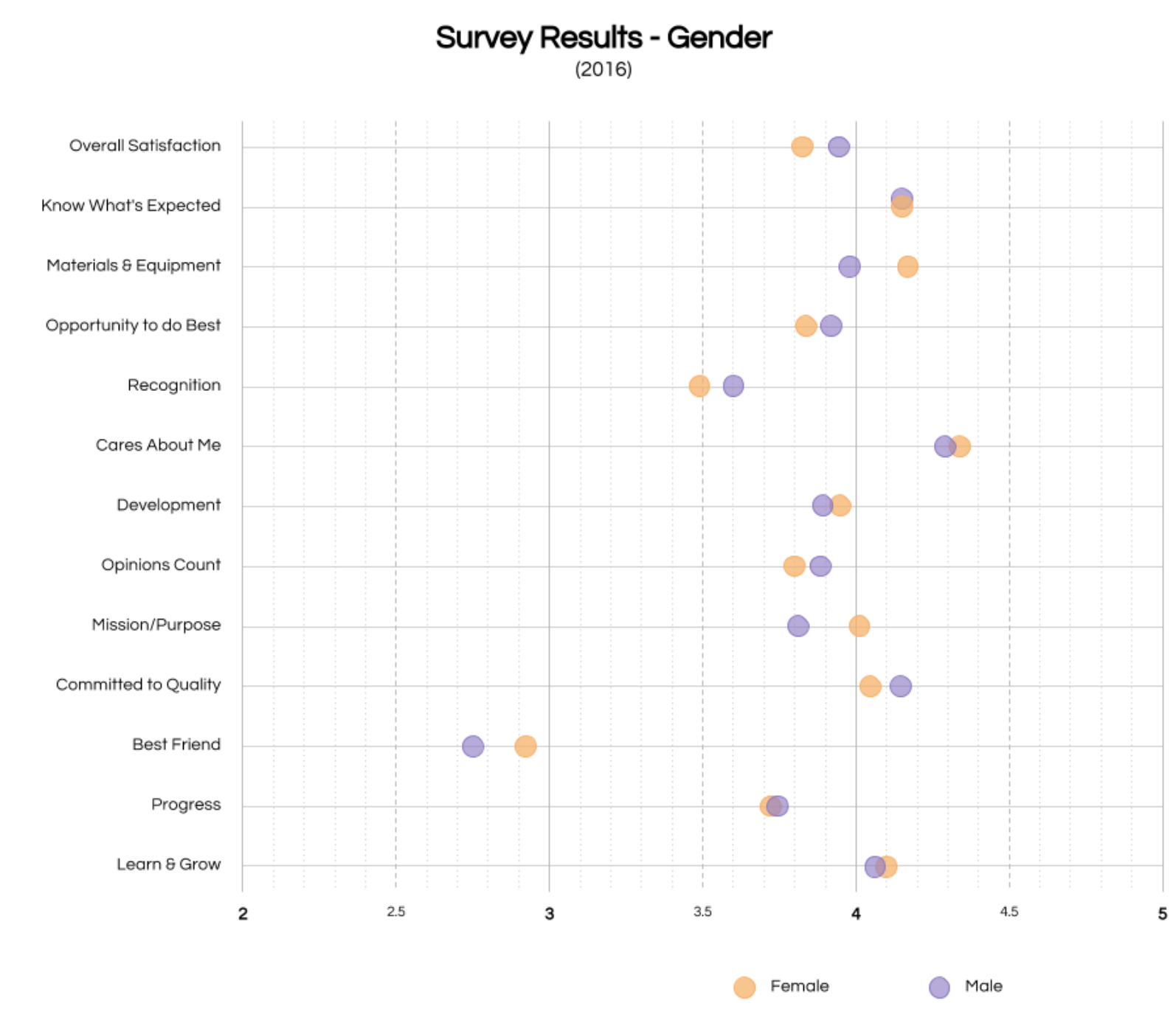

The gender differences are some of the smallest when looking at all 5 demographics. There is fairly even split among who has the higher score between men and women for each question as well (e.g. women have the higher score half of the time, men the other half). The differences seem small enough to not suggest much disparity between genders in how they are experiencing engagement. While small leads, the questions with the biggest differences do all have women with

\begin{tabular}{|l|l|}
\hline Question & Difference (higher score) \\
\hline Mission/Purpose & .22 (Women) \\
\hline Materials/Equipment & .18 (Women) \\
\hline Best Friend & .17 (Women) \\
\hline
\end{tabular}




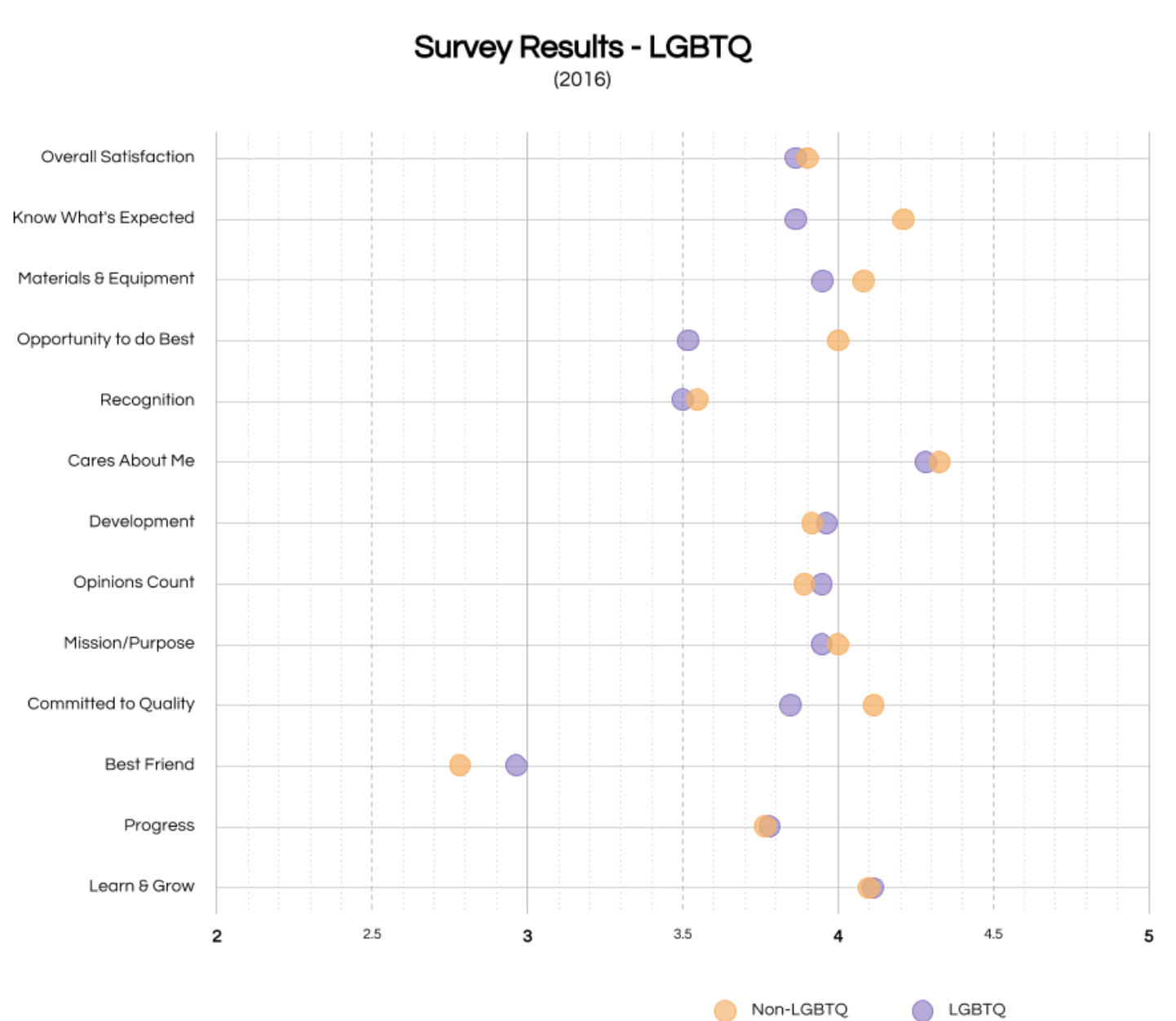

LGBTQ and non-LGBTQ scores were slightly more disparate than gender, with LGBTQ only having a higher score than nonLGBTQ for 5 of the 13 questions (just over 1/3). The most significant differences (below) all had non-LGBTQ employees with the higher scores. Glancing at the data, it appears that LGBTQ employees may be expriencing slightly more disengagement as seen with lower average answers to some of the questions. PSU is known for being a very LGBTQ-inclusive campus, but discrimination and homophobia are still very much alive.

\begin{tabular}{|l|l|}
\hline Question & Difference (higher score) \\
\hline Opportunity to do best & .49 (Not LGBTQ) \\
\hline Know What's Expected & .34 (Not LGBTQ) \\
\hline Committed to Quality & .27 (Not LGBTQ) \\
\hline
\end{tabular}

"If you don't go to work each day and

feel appreciated, that's a problem."

Dr. Kevin Reynolds, PSU Finance and

$$
\text { Administration }
$$

\section{Survey Results - Race}

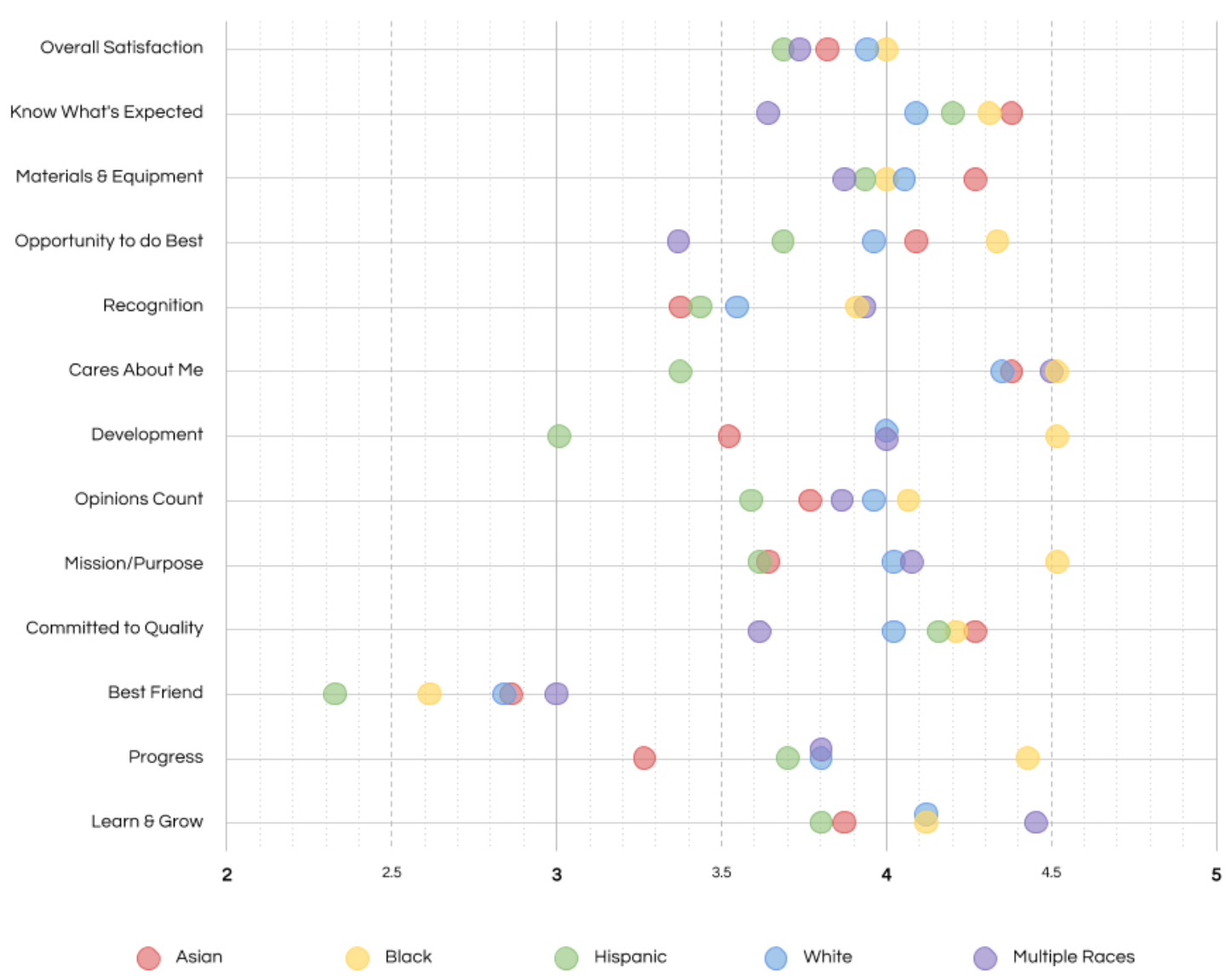


The race data is more varied and has more categories. In general, Black respondents were the highest of many categories including a slight lead in overall satisfaction. Hispanic/Latin $x^{*}$ answers were the lowest overall, and also decreased a lot highest of any category nor are they the lowest this is possibly due to the very large sample size in comparison to other races (respondents were 74\% white, whereas there were many fewer black or Latinx employees, making each response much more weighted). Multiple Races also fluctuated quite a bit between years and by question. While this data widely varies based upon the questions, it is easy to see that some employees of color are at a serious disadvantage when it comes to some critcal components of engagement, especially feeling cared about Below are the largest differences.

\begin{tabular}{|l|l|}
\hline Question & Difference (higher score) \\
\hline Development & 1.46 (hi Black, low Latinx) \\
\hline Cares About Me & 1.26 (hi Black, low Latinx) \\
\hline Progress & 1.15 (hi Black, low Latinx) \\
\hline
\end{tabular}

\section{"People need to feel valued and} honored on the job."

Dr. Carmen Suarez PSU Diversity \& Inclusion d. Years of service

\section{Survey Results - Years of Service}

(2016)

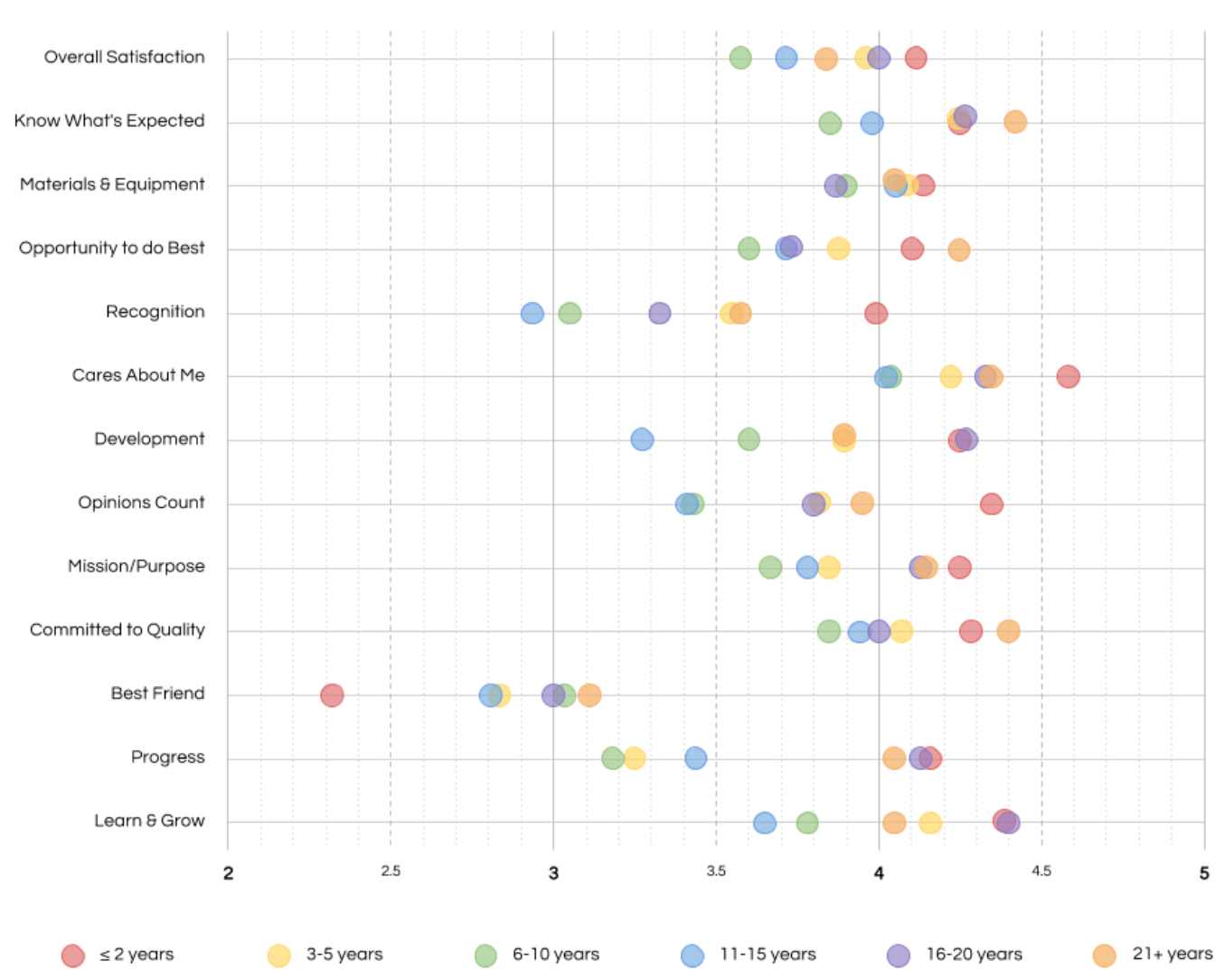

This category was also quite varied. Newer employees (who have been with PSU for under two years) scored highest on "Recognition," "Cares About Me," "Mission/Purpose," "Opinions Count," and overall satisfaction, but quite low on "Best Friend." Contrarily, employees with more tenure (over 21 years) scored highest on "Knows What's Expected of Me," "Opportunity to Do Best," "Committed to Quality,", and "Best Friend". While age is a protected class and a marginalized population, years of service is not itself an MP so it is not focused on in this report. 


\section{CURRRENT CLIMATE AND PRACTICES AT PSU}

“EMPLOYEES NEED TO FEEL, NOT JUST HEAR, THAT THEY ARE OUR NUMBER ONE VALUE."

KIRK KELLY, PSU INFORMATION TECHNOLOGY

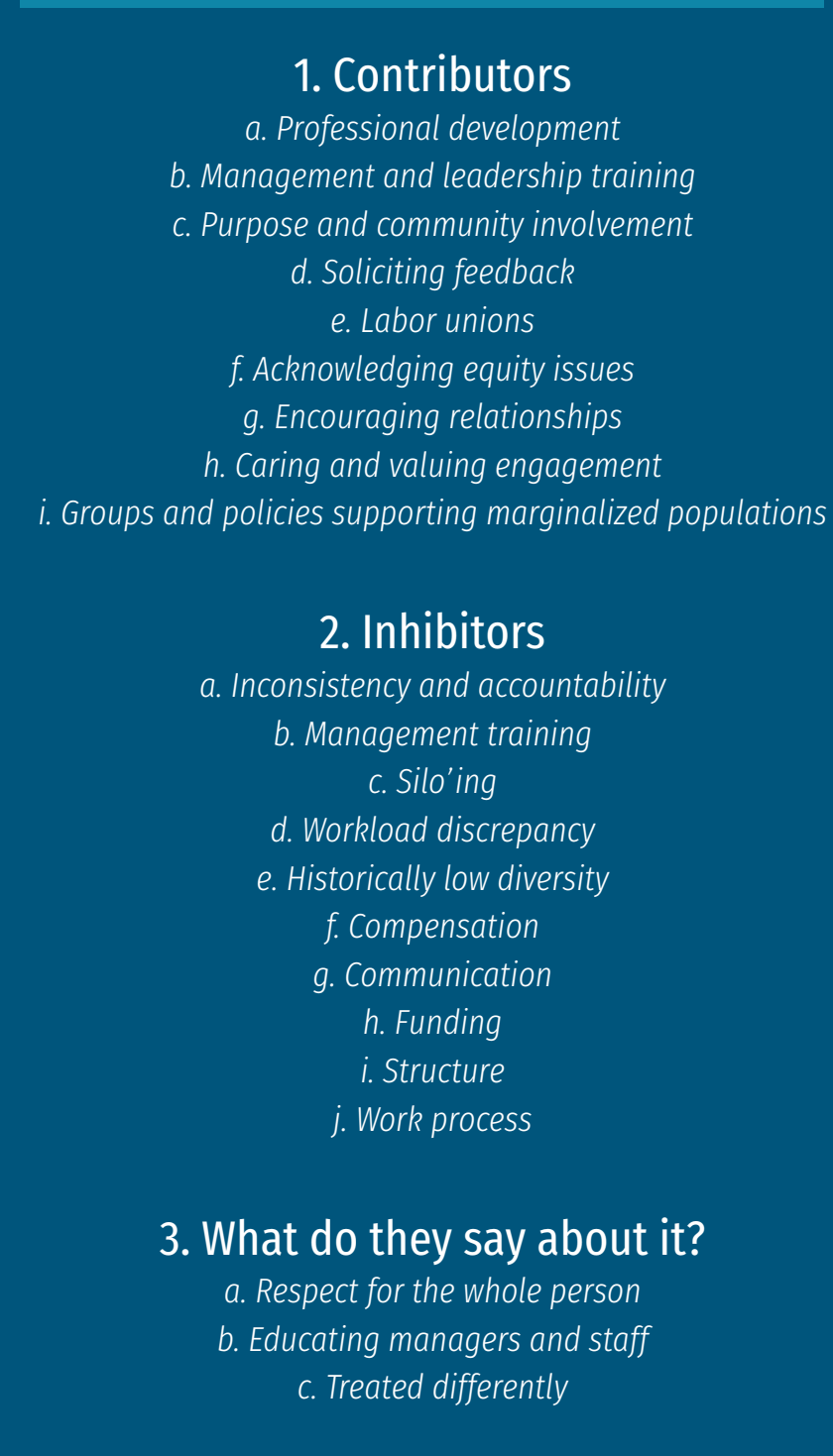




\section{CURRENT CLIMATE AND PRACTICES AT PSU}

To understand the various climates and practices at PSU that contribute to and detract from the university's engagement and equity, 12 PSU administrators in leadership positions were interviewed (summarized in Appendix B); while the information learned from the interviews is represented in the sections below, specific responses from interviews are not attributed to the individual interviewees to maintain some privacy. An anonymous survey of employees who identify as being part of marginalized groups (summarized in Appendix $\mathrm{C}$ ) was also conducted. Below is a summary of the various PSU practices that contribute to and inhibit engagement and equity.

\section{Contributors}

Various departments are effectively supporting employe engagement and focusing on equity for Marginalized Populations.

a. Professional development

Development is a very strong contributor to engagement, and many areas of PSU value this and invest in their employees. While many can think of "professional developthere are many other ways for staff to tate conferences" the technical components of their jobs, to learn the skills necessary for the next job, and to improve on competencies such as conflict management and communication. PSU offers reduced tuition and free auditing, and many free classes ranging from financial wellness to implicit bias. Many managers value and promote education an development and encourage their staff to job shadow, attend local conferences or meetup groups, and participate in cross-training for learning other interesting job skills that can enhance career mobility.

b. Management and leadership training

Another significant driver of engagement is one's manager - the personal relationship, how they treat the employe relative to others, and how competent they are in leadership abilities. PSU has been increasing leadership development in multiple ways. Human Resources offers basic velopment to all managers to focus on both logistics (e

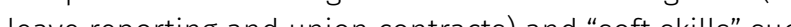

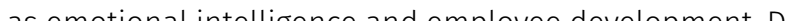

aged and directly solicited from marginalized groups for initiatives such as the strategic plan or campus-wide committees; this helps to ensure a variety of voices are heard Regular meetings between staff and management focus on what employees like and dislike about their iobs and PSU, where they see their strengths, and what is inhibiting them from performing their jobs well. This feedback is taken seriously and acted upon to remove barriers that prevent engagement.

e. Labor unions

Labor unions exist to protect employees and ensure fairness. PSU has many unions, with the two largest being SEIU and AAUP. Unions work to ensure fair treatment, compensation equity, and reasonable working conditions for employees, which are most certainly important components to engagement.

\section{f. Acknowledging equity issues}

Many managers at PSU are committed to acting honestly and in a self-aware manner, and strive to be open about equity and diversity issues. This manifests in many ways, provide implicit bias training having transpart sations a out racial diversity with incoming faculty of color, working with hiring managers on mitigating bias in hiring and encouraging different groups to get together anhave open conversations about issues. The new PSU strategic plan not only has one of its five strategic goals dedicated to expanding a commitment to equity, but highlights an "equity lens" throughout the plan. This is reflective of the PSU's commitment to inclusion: many PSU managers embrace the equity lens and use it to acknowledge and decrease bias or discrimination in their departments.

"THE FACT THAT WE HIGHLIGHTED
EQUITY IN OUR STRATEGIC PLAN
SUGGESTS THAT COMPARED TO
SOME OTHER UNIVERSITIES WE ARE
TAKING THESE ISSUES SERIOUSLY."
DR. MASAMI IISHISHIBA, PSU CENTER FOR PUBLIC SERVIIE

g. Encouraging Relationships

Having strong relationships with management and colleagues (both within one's department and across campus) affects engagement - who wants to come to work when they don't like anyone? Many managers are aware management is a critical trait of a good leader. Hosting department events, having focused but fun retreats, encouragement to attend campus-wide events on work time, attending training or conferences together, and providing space and encouragement for sharing and learning together are all tactics various PSU leadership takes to encourage friendly and professional relationships. Forgsere sense of empathy, and PSU makes an effort to reduce silos by bringing together many different groups to bond over a common goal, be it ice cream, a celebration of employees, or a poster session.

"If you get to know the person or department you're judging you might be more forgiving and understanding."

Ellen Weeks, PSU Information Technology.

h. Caring and valuing engagement

While everyone may not use the same terminology around engagement, many managers value it and are dedicated to providing an engaging working environment. They do this by creating a culture of caring, getting to know their employees and what their strengths and barriers are (including difficulties they face from being in marginalized groups), sending out climate or engagement surveys, encouraging discussion around what can be done better, and in general caring about the employee experience. Good managers across campus invest in and value their employees and create an enjoyable workplace - and understand the importance of doing so.

i. Groups and policies supporting MPS

PSU has many policies protecting marginalized populations, and a strong Office of Global Diversity and Inclusion (OCDI) to focus on equity for students, faculty, and are: Prohibited Discrimination and Harssment policy 
a required training module for all employees, "Creating a Culture of Respect: Preventing Prohibited Discrimination with the Americans with Disabilities Act, Family and Medwith the Americans Leave and Oregon Family and Medical Leave Act religious accommodations; and support for reasonable accommodations and access.

There are many other practices that support MPs. The equity lens also exists throughout the university's strategic plan and administrative functions. OGDI also oversees the Diversity Action Council, which has many sub-commitees that focus on making recommendations to the PSU president for improving the diversity climate at PSU. ManyOGDI trainings exist as well, such as implicit bias and decision-making through the equity lens, and required equity and inclusion training for all academic search committees. Many PSU equity and inclusion practices are for students. but there are quite a few specifically for, or that also support, employees (including faculty, staff, and administration). Some of those are:

Sexual orientation and gender identity are part demographics surveys, partially instigated by 2013's Oregon HB 2995

ing

" Resource centers for students also provide space for staff, including the Queer Resource Center, Veteran's Center, Women's Resource center, Diverairy and Multicultural Student Services, Cultural Resource Centers, a prayer room, and others.

" Annual events like the MLK Tribute, culturally responsive workshops, and President's diversity awards " Community partnerships

» All-gender restrooms throughout campus

" Commission on Sexual and Gender Equity (SAGE)

$$
\text { "Many more! }
$$

PSU is very supportive of diversity, equity, and inclusion, though whether individual front-line employees feel that varies widely and is largely dependent upon their managers and departmental culture.

\section{Inhibitors}

a. Inconsistency and accountability

While the above section highlights some great managethis is self-directed by department leaders, and that the

\section{“LEADERSHIP DEVELOPMENT}

IS PART OF ENGAGEMENT:

YOU WILL NOT BE ENGAGED IF

YOUR SUPERVISOR DOES NOT

SUPPORT AND INSPIRE YOU, AND

SUPERVISORS NEED TO DEVELOP

THOSE SKILLS."

DR. KEVIN REYNOLDS, PSU FINANCE AND ADMINISTRATION

institution lacks ownership or accountability of some engagement efforts from the top. While grassroots, departmental, and "trickle up" initiatives are certainly a part of any organization, a culture of valuing employees must be championed by the organizational leader. While Human is much more difficult to infuse a culture ef valuations, is much more dincult to infuse a culture of valuing real ment opportunities can be offered, all levels of teach must value employee growth and development, encourase their staff to participate, and back it up with resources; while employee engagement scores can be measured white employee engagement scores can be measured,
someone must care enough to analyze the results, talk to employees, and take steps towards improvement

b. Management training

The value of training managers on leadership skills is widely known, but there are many areas on campus where this is not encouraged or valued; an over-taxed Human Resources department or vivides valuable training opportunities, but does not currently have the resources to increase their capacity to do outreach to all of PSU, nor can they simply force the information on unwilling department managers. The employees of these managers suffer and turnover is high; managers are, after all, one of the bigges contributors to engagement and retention.

Many managers are promoted due to their high technical competency, so they are assumed to be able to lead skills it takes to a is observed time and time again, the ckils it takes to empower and lead a team towards sucfrom their manager duties, leaving sorely neglected staff.
Others want to be successful managers but aren't given the tools to do so and unwittingly create inequity and disengagement. While leadership training is available many permutations across campus, it is not universally or department chairs. Training on implicit bias and equity is also inconsistent, which disproportionately affects MP employees who are already suffering the effects of reporting to poor or untrained managers. Lack of knowledgeable, leadership-focused managers is possibly the biggest contributor of disengagement across campus for all staff, and particularly for marginalized populations.

c. Siloing

In a large urban university with so many departments, keeping a feeling of unity is hard. While disconnected office space and full lives outside of PSU can certainly contribute, there seem to be rifts between sections of PSU. Be it faculty vs staff, tenured vs non-tenured faculty, or union vs administration, PSU struggles with in-group fighting that is a frustrating roughout the university.

d. Workload discrepancy

Studies, voices from employees, and confirmation from diversity experts show that many MPs, especially faculty, suffer over-tartion from being a mentor or caring should sufor students who face the same marginalization. This can cause more emotional exhaustion and simply less time to spend on other work, and certainly lead to demoralization. Studies show, and people report, that discrimination and bias mean marginalized employees must often work harder or produce more in order to be seen as equals to other employees.

e. Historically low diversity

It's no secret that Portland has historically been very white, and the implications reach much farther than the demographics. Recruiting professionals of color can be difficul, as the current pipeline of Portland residents is more limted than with other cities. While recruiting nationally is an option, there are also unfortunate issues with people moving to Portland then leaving after a year or two due to the racial diversity and lack of inclusion; getting settled in a new city with no family and significantly less sunshine is who don't senough, but it is even more difficult for those Whoch as they are used to. The low representation in facmuch as they are used to. The low representation in facwith students, providing a understanding that non-mar- sinalized employees may not have. And, since engaged mployees are more likely to make recommendations to eir personal networks for open positions? if there are few MP employees AND they are suffering less engagement then the power of personal references is significant$y$ decreased and the cycle continues.

f. Compensation

Compensation is often an easy scapegoat for low engagement or high turnover, but specifically, PSU has more issues with compensation fairness and inequalities. While unions such as the SElu have explicit pay bands (which of course can have their own issues), other pay inequalities exist between departments or classifications. For example, some faculty are paid for service work, while others are expected to do it as part of their dedication to the university, and the inconsistency can be harmful. Titles and salaries vary for non-union staff with little oversight (though HR is currently participating in a compensation study). Additionally, pay inequality that began, for example, 10 years ago when a woman or person of color was offered less money for equal work continues to perpetuate itself and goes on.

"Communications mechanisms change all the time; just when we think we've arrived, they've changed. We need

to keep reinventing our systems and approaches."

Lois Davis, PSU Office of th

g. Communication

Communication will likely always be a source of complaint in an organization, but psu does have some valid ones. Many employees do not know about the resources available to them (e.g. employee resource groups) due to lack of consistent communication from their own departments, and there is not always a lot of central communication from the university leadership. Sometimes that is due to the fact that communication is done in the way it always has been (e.g. providing answers only when directly asked) and not how employees and faculty want it (digital, easy to find, proactive). However, even trying to find information on PSU's website can be very frustrating. PSU has nearly unteer opportunities, but being able to find them or even where to start is not always easy to figure out. 
In terms of interpersonal communication, this varies wide ly. Some managers (and employees) can have difficult conly responsive, give emotionally sensitive direct feedback mitigate bias in their interactions, communicate departmental and strategic priorities, and keep information flowing among teams; some, on the other hand, don't know the first place to start and it takes its toll on personal and team performance and engagement.

\section{h. Funding}

In the public and nonprofit sectors (and much of the private, to be fair), stress around funding is persistent. While departments may understand and agree that investing in staff development, allowing time away from work to engage with the community, or managers spending more time on leadership training is important, there is also a lot of work to be done with a limited number of staff and funding will likely not be increasing any time soon. Many important priorities combined with very limited budget creates stress around simply being able to keep up with the workthow, much less being able to focus on other things despite tho further the timited funding and unchecked bias can employees, eg more training provided for certain majeople.

"Identifying process inefficiencies is critical to our employees' happiness and engagement. If there is

something broken, then we often

find a complicated workaround that

introduces a lot of pain-points. We

need to spend time examining, pulling

that apart figuring out how to be

$$
\text { more efficient." }
$$

Susan Klees, PSU Finance and Administration

\section{i. Structure}

Bureaucracies exist to ensure consistency across ve large complex organizations like government and public education. However, they are not known for their simplicity, the extra rules that can seem arbitrary to some folks, cromanat or overly constricted unions create an tayer of complexity and rutes on top of existing federat state, locat and PSU policies, and teach is focused on their own members and often not thinking about the demands of others. Unions like the SEIU provide salary banding, but thers are much more varied and not all staff beton to one, so equal payment for equal work is extremely difficult to navigate university-wide.

The academic side of the university certainly has its specific structural issues that can cause even more stress Tenure is a very political and complicated process, as is the nature of research for those faculty and the difficulty of spending a large percentage of one's work applying for grants just to be rejected. The department chair phenomenon is an interesting one as well - one faculty member who is a peer to the others is elevated to being "in charge" for a few years, then seated back at that same level after this "temporary manager" role can create interpersonal ints between colleagues. Additionally, many chairs do not want this role or are not trained on the complications of
managing faculty (training is provided yet not required).

\section{Work process}

One observation by multiple interviewees is the fact that many staff are doing uninteresting or repetitive work. Few work and would rather do something that is chacnin" and enioyable, yet are limited by systems and processes that are in dire need of updating while some can be rethought, there are many examples process improvements that are not possible with the current technoveconstraints, or that require buy-in and work from many different areas that is difficult to instigate.

\section{What do they say about it?}

An informal survey (Appendix C) was conducted on marinalized employees mostly at PSU to examine the effects that their status has on their engagement. Respondents were asked to rank how engaged, respected, and comfortable they feel at work, and responded to open-ended questions about their experiences as well. A full list of questions and some results are available in Appendix $C$.

The survey seeks to better understand the relationship between engagement and respect for being different. Fo the ranking questions, the Pearson coefficient " $r$ " was used to compare correlations between the data sets; igher number means a stronger correlation between the cally significant correlations between neary all questions at the 0.01 significance leb. Self-rating of engagentions which the survey is most concerned with, was significantly correlated with "I feel respected for my differences by my manager $(r=0.519)$," "I feel comfortable speaking up again fortable speaking up against the status quo to my coworkers $(r=0.546)$ " The only lesser significant correlation was between engagement and "I feel respected for my differences by my coworkers" $(r=0.410)$.

What does this mean? The strongest correlation (.799) shows that employees who feel respected by their manager are also those who are comfortable speak up against the status quo; one reason for this could be that they feel more safe being their true selves at work, or are more comfortable being "different." There was also strong (.776) correlation between speaking up against the status quo to managers and to coworkers. This could be explained by managers strongly affecting the culture of the team; a fairly strong correlation between how comfortable on is being "different" exists between management and colleagues. The data suggests that a respectful culture an relationships wh manasers, and to a lesser degree relatonships with coworkers, are crucial in feeling engaged.

The full pairwise correlations are available in Appendix $C$ The results are unsurprisingly similar with the feedback nificantly affected by how respected one fels for their differences, and how comfortable they are being different It seems, therefore, that how included one feels, how supported they are in showing up as their "whole selves" even if that is different than others, is a strong contributor to engagement. An inclusive culture, where managers an coworkers respect differences and encourage constructive discourse and dissent, is important for engagement: those who are part of marginalized groups will be affected the strongest by an uninclusive culture.

Below are a few quotes by some of the 25 respondents. It is clear that discrimination is very real to PSU employees, which impacts their engagement.

a. Respect for the whole person

"When I feel valued and appreciated for the perspective bring it is highly motivating. When I leave a meeting with executive leaders who have talked over me I feel very discoureged and den who have talked over me I feel very disex such an experience.

"Not being understood or respected creates massive barriers to engagement. It can push people (me) into disthe sense that PS -as represented by its management and culture--doesn't seem to care (while continuously claiming to respect these differences) can be demoralizing at times"

"After I started transitioning at another institution and was relatively welcomed and accepted, I found that my productivity and level

"I can't talk about my real social life. I am not out."

b. Educating managers and staff

"It seems that many of our managers aren't really interested in managing people/projects and would rather be doing hands-on work."

PSU should continue to promote diversity and acceptance through education and awareness programs and shoutd continue to promote hiring of diverse/marginalzed groups."

Ithink it is important for people to realize the privilege they have, and to hear more about the experiences of

More training for upper management on supervising diverse populations (including marginalized groups)."

c. Treated differently

'There are definitely times I feel ostracized if I'm in a meeting with a group of men and I am the only woman at the table. A recent example is being first to a meeting to evaluate the potential equipment needs of a space. I ended up being the only woman present, and as the others
came into the space they circled up and literally left me out of the group until I said something."

feel discouraged to engage with other employees that produce microaggressions."

I have experienced being talked over in meetings despite the fact that I am in a position of leadership and a subject matter expert."

'I get frustrated by others' behavior towards me (such as making comments about my body, which has happened at work at PSU) or feeling like lam not taken as seriously as I ould be as a man, and then I feel less engaged:

"I would feel more welcome overall if I never felt like I had "I fight for a place at the table, or for my turn to speak in a the flow, even if it mit's eas staying quiet or being gowth" 


\section{RECOMMENDATIONS}

"ONE OF THE KEY ANSWERS TO STAFF ENGAGEMENT IS SHOWING FRONT LINE AND NEXT LEVEL MANAGERS HOW TO BUILD COMMUNITY, HOW TO MANAGE A DIVERSE WORKFORCE." DR. CARMEN SUAREZ, PSU DIVERSITY \& INCLUSION

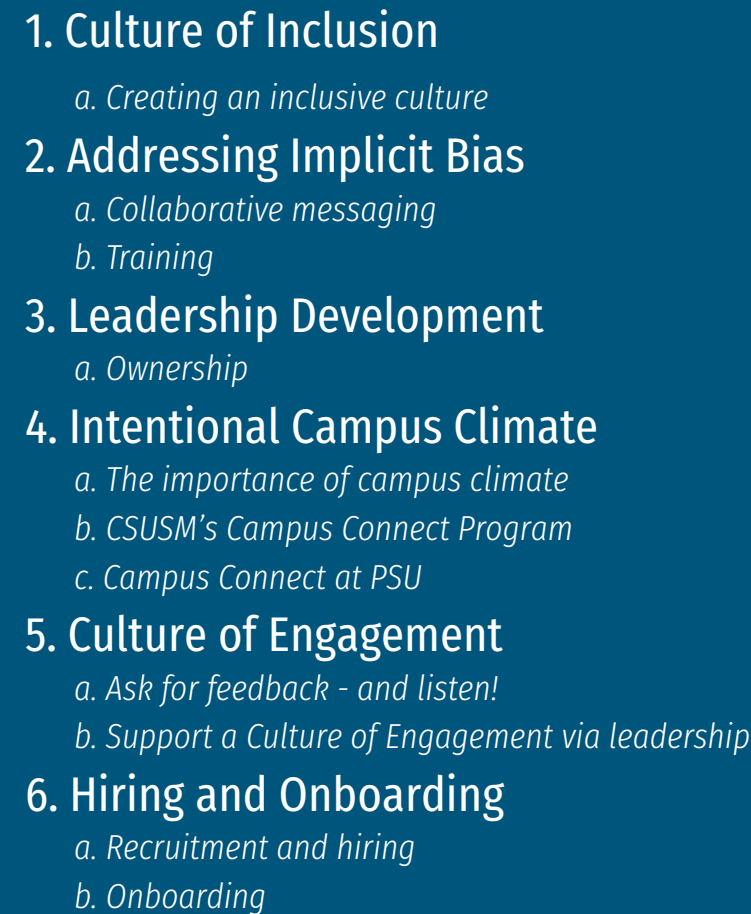

7. Data-Driven

8. Strengthen Trust

9. Autonomy

10. Purpose, Connection to PSU's Mission a. Public Service Motivation

b. Managing for purpose c. Hiring for purpose

11. Invest in Development

12. Communication a. Two-Way communication with staff b. A culture that values and encourages communication 13. Relationships a. Encourage relationship-building b. Build relationships for future students, employees c. Invest in programs 14. Actual work 


\section{RECOMMENDATIONS}

Between peer-reviewed research, numerous articles by trusted online resources, and suggestions by PSU administration there are many opportunities to improve PSU engagement through the equity lens.

\section{Culture of Inclusion}

The most impactful way to create a better environmen for all employees is through intentionally creating an in clusive culture. A diverse group of employees is the result of an inclusive culture; many studies and articles tout the benefits of diversity, such as increased performance, innovation, creativity, engagement, cooperation, decreased stereotyping, readiness for change, financial strength, an more accuracy a resilcent wa" when ropulated by people wh diferent an inclusive, diverse culture, and particularly when comparing them to the negative side effects to the lack of on(as discussed in the Employee Engagement and Marginatized Populations section above), it becomes exceedingly clear that fostering this culture is a crucial part of engagement that benefits all employees.

\section{"IF YOU CAN GET TO A SPACE}

OF LEARNING AND TRUST AND

ACCEPTANCE, THEN WE CAN GET IT

WRONG SOMETIMES. THIS ALLOWS

US TO THEN TAKE MORE RISK, TO

SOLVE BIGGER PROBLEMS, TO BE

ABLE TO MAKE MISTAKES IN THE

PURSUIT OF EXCELLENCE."

SUKHWLNT HHAJ, PSU ACADEMIC INNOVATION mendations $26,2,7,8$. Oregon State University, for example, has multiple positions inside of departments that work closely with the University-wide Office of Diversity and Inclusio but who are focused on their particular departments. Researching published reports or leaders of other organizations will give some good perspectives that can be used alongside internal PSU direction. Focusing on creating this ly populations who face exclusion on a regular basis.

"Engagement in higher education involves creating an inclusive organizational culture, one that is respectful and hospitable to everyone." Anne Gillies, Oregon State University

\section{Addressing Implicit Bias}

Implicit (or "unconscious") bias exists and has negative impacts on employees ${ }^{28}$ and particularly comes out when making quick decisions, such as when making interview judgements or during conflict ${ }^{29}$. As awareness around this unfortunate phenomenon becomes more popular, the common answer is implicit bias training, which is required Awareness is the ans, including University of Oregon. attend a training will not solve this problem

a. Collaborative messaging

Like an inclusive culture, learning how to "bias check" does not happen by simply hiring more "diverse" enployees or telling staff they aren't allowed to make discriminatory jokes. It is intentional and must be handled with empathy, understanding, and in a safe environment. Steps to reducing bias certainty do not include ostracizing others in positions of privilege (e.g. men, able-bodied, or cis-gendered people) with an accusatory tone; this leads to defensiveness, divisiveness, and can create significant harm. Addressing bias and slowly excluding it from uncon-

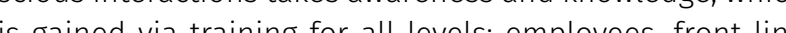

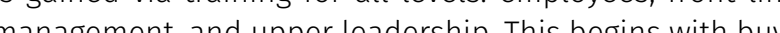
in from the top of the university and requires departmenat manasers to be on board as well Simply saying all en- ployees must attend a "sensitivity training" will probably result in grumbling employees and possibly a backlash to being told they are currently doing poorly at this topic Contrast this, however with a leader who works with trainers to create focused sessions, communicates the benefits (e.g. how to create a better pool of applicants, tools for having difficult conversations or constructive dissent) who is eager to learn themselves, and who has communicated that they value equity and inclusion in other aspects of work and not just an out-of-the blue training. Employees can tell when leaders are genuine and live by their values, and this is no different.

The relationship between leadership (and even employes) and those doing the training must be strong and focused on understanding and a willingness to work together to create positive change. This means not just decreasing bias, but encouraging an inclusive culture. Trainings must be useful and create a safe environment in which to explore a difficult topic, including reserving judgement when people "get it wrong" - after all, the point is to learn and must b. $\mathrm{pR}, \mathrm{OGDl}$, and individual department leadership

b. Training

Creating a culture of value, buy-in, and education about equity and eliminating bias is a very complicated discussion that many organizations, most certainly universities, are having right now The answer is in positive, collaborative messaging mixed with education. Make trainings available to all and make them digestible - this includes mixing theory with practice, focusing on the benefits, and giving managers tangible tools that they can take back to their

\section{"PEOPLE WHO LOVE THEIR MANAGERS LOVE THEIR JOBS. HELPING OUR MANAGERS BE BETTER AND MORE EFFECTIVE IS ONE OF THE MOST SIGNIFICANT THINGS WE CAN DO FOR ENGAGEMENT."}

SUSAN KLEES, PSU FINANCE AND ADMINISTRATION 
everyday work. Include the bias perspective (or equity lens, as PSu does) in all types of conversations, such as whe training materials, or when hiring - not just when it's time for an implicit bias training. Create a Search Advocate Program ${ }^{30}$ (which has recently begun at PSU) to not just benefit recruitment but to spread information to those who can then help to reinforce that culture. Inclusion training is already required for faculty searches, and implementing a Search Advocate program at PSU will hopefully encourage all university searches to have a partner in inclusive, consistent, and effective search practices. Give employees tools to constructively call out potential bias when they see it happening to themselves or their colleagues.

Training is more effective when focused on individual stories, as it provides a sense of empathy needed when discussing these topics that speak to both the logical and emotional side of bias. For example, a recent training a PSU showed someone who couldn't use a mouse due to physical constraint and what that person's experience is in trying to navigate their online needs. This was far more effective in helping those at the training understand why them a set of rules to follow. Focusing on the why, a tenant used in parenting and teaching for centuries, is a much more effective focus for changing culture than simply telling employees or eadership to do something understanding what MPs go through can give managers a different perspective and better understanding of their employees, and training can help them avoid negative behaviors.

\section{“THERE IS REAL CORRELATION \\ BETWEEN QUALITY OF THE \\ IMMEDIATE SUPERVISOR AND \\ PEOPLES' EFFECTIVENESS, \\ PRODUCTIVITY, HAPPINESS, AND \\ DESIRE TO STAY AT PSU. IT IS TOO \\ IMPORTANT TO OUR ROLE TO NOT \\ FOCUS ON IT." \\ SUSAN KLEES, PSU FINANCE AND ADMINISTRATION}

An understanding of implicit bias is essential for marginallzed populations being treated fairly. The more bias th more disengaged they will become Bias in the hiring process can prevent MPs from even entering the workplace, and will push out those who are experiencing it while some discrimination is intentional, many would argue that most is not. Acknowledging unconscious or implici bias can help to decrease it, and training employees and managers to recognize their own biases and analyze their own interactions will greatly decrease the inequity in the workplace. This will have a very strong effect on the engagement of those who are being discriminated against.

\section{Leadership Development}

Aside from working with leadership on acknowledging bias and inclusion, managers also must know how to manage. is far too frequent of an occurrence that those promoted to management are the most tenured or technically competent, but that does not speak to one's ability to understand how to effectively manage other people. While a university must also provide practicat guidnce and tranining, PSU leadership and management techniques (e optimistic managers create better performance and more workplace optimism, which will increase engagement3it how can we hire for that?). As mentioned in above sections, many efforts around this currently exist in different areas around campus. The knowledge is becoming more avalable but as always, the struggle will continue to be proactively getting those who need it to participate. PSU administration can help by providing assistance to managers who are suffering from disengaged employees, be it from a training class or one-on-one help.

a. Ownership

there is no position responsible for equitable engagement to work with departments on leadership development and training managers, then who will have ownership over this extremely important role? If this is truly valued by the university, designating how this work will get done (and by whom) is a must. Researching best practices may be somewhat simple (research is out there in droves and many companies, now including Google ${ }^{32}$, publish their materials), but getting buy-In with shared governance, understanding the nuances between microclimates, enclusive engagement and being able to navigate the poitics are ener-present chaltenges. Designating on therhip for consistent readenship devesopment centrally or whiph departments is essential but cannot happen without difrion from the top, and must be lead by the right person focused on collaboration and not enforcement.

Buy-in from the highest university leadership around this topic helps enormously as those people can encourage or require those below them to attend leadership training live and lead by example, and make sure to hire, promote, and train inspirational, caring managers who embrace the values and culture of the organization. A workforce of engaged employees simply cannot happen with poor leadership - not just at the top of the organization, but managers of front-line staff as well. "Leaders have the greatest influence on employee engagement in the organization. Organizational leaders who cannot answer the question 'What am I doing to properly engage employees?' are not doing enough to address employee engagement. Leaders cannot require employees to engage".". Leadership must

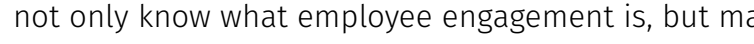
an intentional effort to create a climate that values it.

\section{Intentional Campus Climate}

Successful efforts around employee engagement, such as California State University: San Marcos (CSUSM), show th ened by all levels of leaderhsip, including the president CSUSM provides a good example and successful strategies around creating a positive, engaging campus climate.

a. The importance of campus climate

CSUSM president Karen Haynes has established Campus Climate as one of the 5 university strategic priorities ${ }^{33}$ and takes it very seriously. Culture, while it can be tricky to define, is integral to success ${ }^{34}$, and CSUSM understands that well. "Positive cultures, where people feel empowered, and part of the greater scheme of things, are more successfu. forming elements of culture that can be seen in high performing councils include a can-do culture where people don't ask for permission to innovate and a buzzy culture that is recognisable, and are generally upbeat and positive. The ability to re-invent, re-energise and keep meeting and communicating as well as having a friendly, supportive and high performance culture are also common elements. A positive, inclusive climate strongly affects employee engagement and satisfaction. For staff, climate is largely facuped by close coworkers they interact with every and acceptance, as well as curviculum and university supand acceptance, as well as curniculum and unversity supdepartment versus a small program).
Climate is not just university-wide, but exists in many permutations called microclimates, such as based upon department or membership to an underrepresented group; being out as LGBTO or as certain religions or political affiliations, for example, can be safe for one person but not for others. A Culture of Caring ${ }^{35}$ is highly valued in some areas, while others suffer micromanagement and are "motivated" by fear of punishment. The university should acknowledge and measure microclimates's, and work to infuse the positive ones across the whole organization.

"The University as a whole has a community engagement aspect; we need to continue to work with community partners, and find opportunities for faculty, staff, and students to collaborate with the community."

Lois Davis, PSU Office of the President

b. CSUSM's Campus Connect Program

One of the campus initiatives ${ }^{36}$ that has brought great success in terms of forging relationships and creating engaged employees is the Campus Connect program ${ }^{37}$. Championed by the Associate VP for Campus Climate \& Chief of Staff Jennifer Williams and Associate Vice President for FAS Administration Katy Rees, this program “aims to enhance a positive campus climate by achieving the following objectives:

1. Instill a deeper understanding of the CSUSM Culture 2. Increase awareness of job functions across divisions and departments to highlight the interdependent nature of everyone's work

3. Develop an appreciation for the complexity of the institution

. Create a cadre of "ambassadors" who will share insights, clarify misconceptions and communicate information about how the university works"

Each year, a cohort of 30 university employees (selected via an application process) meet as a group for one morning a week for 10 weeks in a row. They meet with the president and other university leadership, learn about the university's culture, spend time all areas of campus (e.g. facilities, to met others across campus and forge imping), and get ing relationships. The program is a two year commitment graduates of one year then go on to lead the program of the following year. Campus connect directly supports 
the President's Campus Climate initiative, and employees know that these initiatives are valued. Graduates of the the program who then energize others ${ }^{38}$. Informal workplace networks are essential to solving problems finding information, employee satisfaction, and retentions.

Ms. Williams and Ms. Rees speak for about 20 minutes on an education-focused podcast ${ }^{39}$ about their cultural initiatives that is highly worth hearing. A snippet of the information packet is attached in Appendix $D$.

\section{c. Campus Connect at PSU}

While culture is not one size fits all by any means, similar programs have been successful across other campuses and it is highly recommended that PSU seriously consider something similar. However, this will not be as successfu if owned by a single department, including HR - valuing culture and getting others on board with a program like this simply must be a usisersity intrative, and requires a high-level campus champion as with CSUSM.

\section{Culture of Engagement}

Many PSU departments are successful by embracing a culture that values employees and their engagement, such mation Technology, and Office of Academic Innovation. To further spread success, these principles should be messaged across campus to continue a culture of valuing and respecting the humans behind a successful university.

a. Ask for feed back - and listen

Management and administration should ask employees for their input and what they need to be successfulto, including letting them drive employee engagement efforts 6 . Empower optimism, seff-efficacy, and self-esteem in employees ${ }^{4}$. Give them feedback, autonomy, and support so that they can take care of themselves (physically and mentally) and not face burnout and related health issues. ${ }^{4}$. Understand the right level of engagement that encourages their "flow" (the right amount of challenge and ability 10 ). Managers across the university who ask their employees how they feel, what they need to be successful, and respond to that feedback can attest for a dramatic improvement of mention it's the right hing to do for that follow - not time communicating, connecting respecting and teaning thout others is the first step to understanding their needs and how they can be supported
There are many ways that PSU leadership can support a culture of engagement. Train managers how to create a caring, respectful culture to promote engagement16.3. Empower HR to be an employee champion (through initiatives like effective performance management and evaluating the work environment) ${ }^{4}$. Make organizational decisions with the employee experience in mind, and measure manager's success in part by how well they foster an engaging environment, including helping them form an employee engagement action plan (which, again, must be "owned" by someone at the university) $)^{8}$. Lead by example and show employees their recharge time is valued, including not working on evenings or weekends and taking real vacation time each year to disconnect. Find others with a high-functioning, engaged team (either at the university or at other organizations) and ask about their methods. Investigate or collaborate with universities who have employee experience in their university strategic plans or initiatives, such as CSUSM "Campus Clmate," University of Britis Columbia "Outstanding Working Environment,", or Orego State University's "Improving Human Health and Wellness." PSU, but once again, they do not reach all correctices at university, which is an issue at PSU.

"LISTEN, REALLY UNDERSTAND WITHOUT DISMISSING, FIND WAYS TO FOLLOW THROUGH WITH IDEAS HOW TO HELP MAKE WORKLOADS

\section{MANAGEABLE, AND ADDRESS} CONCERNS."

DR. KAREN MARRONGELLE, PSU LIBERAL ARTS AND SCIENCES

\section{Hiring and Onboarding}

While engagement and inclusion are generally looked at in terms of current employees, it does a great disservice and onboarding process, and many departments at PSU have a lot of room for improvement.
Recruitment is not just an opportunity to find qualified candidates, but to try to attract them with PSU's culture The job advertisement including qualifications, is the first interaction that potential candidates will have with PSU, and it is a crucial yet often hastily compiled step. Overly-limiting qualifications that require strict experience keep a diverse range of candidates from applying and putting to use their different sets of skills. This disproportionately affects candidates who had difficulty acquiring certain education or joining particular fields of work, who will then have less of a chance to demonstrate their qualifications. Hiring for more than just technical qualifications or years of experience - such as attitude, cultural fit, ability and motivation to learn, or a service mindset - provides richer, larger candidate pool, better variety of applicants. and more successful employees

Interviews should also be welcoming and inclusive, an hiring committees should reflect a variety of voices includ ing education, department, background, and voices that are often unheard. If a woman or person of color were the well to the diversity values of PSU and may cause them to second-guess accepting a job. In terms of the actual nterview components, requiring candidates go through a ganntlet that is no reflection of a day of actual work in their iob is misleading and can turn off candidates who would otherwise had been eager to join $n^{4}$.

Though it was many years ago, the Wisconsin State Government managed to very successfully revamp their bureaucratic and unwelcoming hiring process to be one more focused on the applicant experience ${ }^{46}$. They eliminated pain-points, such as a long application process and excessive interviewing, which was done by soliciting and incorporating feedback about the process. They also started an entry professional program, including training graduate students, that resulted in more diverse and more qualified ap plicants who were receiving a chance that they may have not had otherwise. HR could certainly solicit and incorporate feedback about the overall application and hiring process, and advise departments on best practic, which vary widely by department type of position.

Hiring for purpose, or Public Service Motivation (PSM), will result in more engaged, dedicated employees; this is particularly true for leadership, as those positions positively tion's performance when they hof

\section{"SALARIES AREN'T THE RESOLUTION \\ TO ENGAGEMENT. THE HIGHEST \\ LEVELS OF ADMINISTRATION \\ MUST VALUE WHAT OUR \\ EMPLOYEES THINK, WHAT THEIR \\ WORKING ENVIRONMENT IS LIKE, \\ UNDERSTAND WHAT WE'RE ASKING \\ THEM TO DO AND THE CHALLENGES THEY FACE IN DOING IT." \\ SUSAN KLEES, PSU FINANCE AND ADMINISTRATIOI}


are motivated to mobilize their own daily job resource in order to stay engaged and perform well4. A candidate be more motivated to learn and contribute their energy towards their job, whereas someone technically competent with lower PSM may know more in the short run but will likely be less engaged and contribute less in the long run. Recruiting those who already have high PSM or a hig connection to the university's mission, then continuing to build on that motivation via community engagement, will be to great benefit for the university. First, that requires departments understand PSM, then incorporate it into their recruitment process

Viewing the entire recruitment process through the lens of inclusion and engagement is important for attracting the right candidates with diverse perspectives, who will have high standards for an employer, and who will align with

\section{b. Onboarding}

Good, thorough, and organized onboarding is essential for new hires to feel welcome, understand the organizatio knd stay retained ${ }^{4}$. Guid to ensure departments are consistently offering a positive onboarding experience to all employees, such as good communication practices, preparation (es. requesting access in a timely manner and having the workspace set up). and creating a welcoming environment.

For some marginalized groups, the onboarding process can be even more important or, at times, tricky. All of the issues with being an MP in the workplace apply, but when it is a new employee, these issues can certainly cause someone to leave due before they have a chance to find community, settle in, and find their space. For example, people of color who are just moving to Portland may have a whiteness culture shock; finding groups such as Say Hey!lis or the different resource groups on campus can help. New employees may not have any idea how to start finding communities to join, so this information must be communicated proactively, such as in a central location

"THE QUICKEST WAY TO CHANGE CULTURE IS THROUGH HIRING." KIRK KELLY, PSU INFORMATION TECHNOLOGY on PSU's website and through resource groups. This can be difficl since there is so much information at a lars perience in mind when doing onboardins. this includes a focus on things like community, engagement, and PSM i addition to actual job knowledge.

Some departments have successful buddy programs, which is one of CSUSM's successful contributors to their culture as well. Buddy programs partner new employees with other engaged university employees (in the same department or not, depending on the program) who act as an introduction to the university life and culture, including things like where to eat lunch, political conversations to avoid, and other topics that a new hire may not necessarily ask their manager about. Having a structured buddy to touch base with not only gives new employees another resource, but also provides an opportunity for service and connection for the more tenured university employee.

\section{Data-Driven Decisions}

The Gallup Q12 has been a great start to understanding engagement at PSU for those that have taken it. The lack of significant differences further analysis around statistically are experiencing Paying for the additionat data will be very helpful in further exploring this topic. Furthermore in order to understand engagement in other areas of the university, some sort of engagement or climate survey should be taken regularly (not necessarily the Q12, though that is one successful option) and acted upon, including making the findings transparent (which will build trust and accountability). A path for improvement requires a form of measurement, and engagement can be measured ${ }^{5}$. Conducting a university-wide engagement survey would no only help leadership to understand PSU's overall engagement, but understand more about different departments, job types, subcultures, marginalized populations, and more. Atter the data is gathered, more specific recommendations for what or where changes should occur can begin.

Another way of measuring data around engagement is finding out why people are disengaged by conducting consistent exit interviews. Of course, not all employees will want to provide feedback, but regularly asking all exiting staff a few questions and getting a better understanding of what is causing them to leave should be on the top of departments, but can be with upper leadership in some cepartments, but can be with upper lead Finance and Administration conducts ext isterviews for that entire unit). Exit interviews are on the currently Diersity Action Council (DAC) Annual Reportt9 and the DAC Recruitment and Retention of Diverse Staff sub-committe 2016-17 report ${ }^{50}$.

"After seeing the survey results from the last couple years, we now need to move our thinking from "we need to improve' to "here's how to improve."

sarah Johnston, PSU Human Resor

\section{Strengthen Trust}

Employees in high-trust organizations are more engaged, more productive, have more energy at work, collaborat better with their colleagues, and stay with their employers longer than people working at low-trust companies. They also suffer less Chronic stress and are happier with their lives, and these factors fuel stronger performances. The not easy. PSU must intentionaly create this CSUSM had success when their president championed this effort in cluding holding open forums, caring about the employes, following up, and creating the campus connect program to break silos and increase empathy between people.

Trust (which includes fairness) is particularly important for engaging marginalized populations $5^{22}$. Inequitable treatment alone is a breach of trust, but especially in an organization that touts strong commitment to inclusion, as inequitable treatment would seem even worse. Managers must not only avoid treating people unfairly, but believe and quickly respond to reports of discrimination.

To remain engaged, employees must trust that the organization is fair, which ultimately means trusting in management ${ }^{53.5}$. One way to get employees to trust the organization is for management to first trust employees. Untrusting management includes lack of self-awareness, being riskaverse, and having a bottom-line mentality; good examples, on the other hand, include taking stock of the current climate, carefully giving up control, sharing information, pushing for needed change in response to feedback, and investing in employee develop re

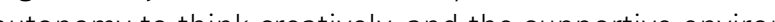
ment that will facilitate their engagement.
“TRUST IS EARNED. YOU CANNOT JUST CREATE THE SPACE AND SAY "WE WANT TO ACT OR WORK IN A CERTAIN WAY" AND EXPECT THE COMMUNITY TO FOLLOW. YOU HAVE TO SHOW YOU WILL ACCOMPLISH THE THINGS YOU SET OUT TO DO." SUKHWANT JHAJ, PSU ACADEMIC INNOVATION 


\section{Autonomy}

According to decades of research on Self-Determination Theory (SDT), autonomy is one of the pillars of human moin depth, along with mastery and purpose (SDT's " competence" and "relatedness"). The research strongly shows autonomy is important for motivation and engagement".

Providing increased autonomy to employees can be difficult for managers who manage via control. Autonomy is the opposite of micromanaging; to give reasonable autonomy, managers must trust employees, communicate expectations, and give them the tools they need to succeed. increasing autonomy is not difficut if departmental leadership helps managers understand the benefit and tactcal ways to do this. One way to do this is via more flexible work schedules for staff when possible, which will also increase the range of diverse employees ${ }^{8,40}$. Setting and communicating clear goals (not assigning tasks), giving employees the autonomy to reach that goal, and providing consistent feedback throughout the process is a successful way to not only facilitate engagement, productivity, and movation, but also trust. Staf must feel enpowered to essential part of innovation and learning).

10. Purpose and Connection to PSU's Mission

Purpose is a very impactful driver of engagement and motivation ${ }^{10.5}$. Some departments have a closer connection to the purpose of the university (e.g. academic departments), and others are unfortunately a few more degrees of separation from teaching and learning (e.g. back-end IT). Bringing work back to the mission whenever possible has been successful for many organizations and PSU departments and should continue to be a focal point for administrators and managers, especially those in departments or roles that may not have as much face-time with students an faculty. Meaning can be found by connecting with end-users and hanng a sorvice mindset, even for jobs that are typically thought of as less meaningful ${ }^{58}$ but certainly for

a. Public Service Motivation

Public Service Motivation (discussed in Chapter 1) can be maximized through many of the other inprovements tively, manage employee performance, ensure employees believe their opinions count, create a more positive work environment, provide a positive onboarding experience, ents for career growth, and recognize employee contributions are linked to performance ${ }^{13,4}$.

b. Managing for purpose

Managers can remind their staff of the impact they have on the university, including regularly sharing positive feedback from students, faculty, and other staff. Volunteering at or attending events that brings people together across departments for a greater purpose is a very successful way to develop overall community engagement that also helps build relationships (below). PSU has many opportunities for faculty and staff to serving the student community, such as monthly Harvest Share, annual commencement, and many others; managers should provid encouragement, work time if reasonable and appropriate, and lead by example. CSUSM's Campus Connect program is highly focused on purpose, and one of its outcomes is connecting people to the university's mission. Leadership can work with employees to go from a job mindset ("it is my jays into do $A, B$, and $C$ ) to a career mindset (this role plays in mo my career goals by giving me $\mathrm{D}, \mathrm{Q}$, and R skills") doing $X Y$, and $Z^{\prime \prime}$ ) through helping employe the broader impacts of their jobs Lack of connection to mission and purpose is a frequent cause of turnover. If managers are the main source of that connection and they are also spending less time with their marginalized em ployees ${ }^{14}$ that means an already disadvantaged population may be getting even less of this essentia connectio-

"THE OPPORTUNITY THEY HAVE TO

INTERACT WITH STUDENTS AND

HEAR FROM STUDENTS ABOUT HOW

WHAT THEY DO IMPACTS THEIR

ABILITY TO COME TO SCHOOL OR DO

WELL HERE IS REALLY IMPORTANT."

DR. ISAAC DIXON, PSU HUMAN RESOURCES
Millennials are becoming a larger and larger part of the workforce, and are known for being very purpose-driven. They are known to value purpose over profit, and want to work for companies who do the same ${ }^{59}$. Recruitment and interview processes should clearly focus on the mission of the university and help applicants understand the type of impact they will make on others' lives, not just focus on the technical duties of the position. Searching for those who have a strong connection to purpose will ensure ployees sentration of purpose-driven, PSM-focused emgloyees who want to dedicate their energy towards the greater good. Leadership must also do its part by ensuring ty's purpose ${ }^{10}$

\section{Invest in Development}

One of the strongest drivers of employee engagement is development - "stuck" employees who feel undervalue simply will not be as engaged in their jobs and will either be far less productive or simply leave. As the quote (ofthan training your employees and having them leave is not training them and having them stay" Investing in enployee development shows that they are valued $\mathrm{d}^{54}$ whereas refusing to provide them the money or even time to deveop shows quite the opposite. Employees who have been historically marginalized and received less opportunity for growth should be given the same opportunities, and if they have less experience with development activities, they may need more encouragement Leadership and employees must share an active role in employee development, and the onus cannot land solely on either party". As many managers at PSU know, it is, however, leadership's job to help the employee realize their career path at the university, understand what options are available for onthe-job development, and to invest time and financial resources into their employees. Development is also a key component of trust

“We don't have a lot of clear paths for professional progression in some areas, so we lose good people. Kassy Fisher, University
While some departments are great at this, again, it is inconsistent. HR can help all managers by providing guidance or training on how to develop employees, such as with employee development plans or recommendations for on-the-job training ideas, which can include different assignments, leading a committee, or providing a training ${ }^{61}$. Strengths-focused development leads to better performance and higher engagement, instead of just focusing on lacking behaviors that need improvement ${ }^{65,56}$. PSU leadership must value and invest in development for its employees, and do so consistently.

"How can we improve things so that we can spend more time on development and impactful work and less time on low-level tasks?"

Sarah Johnston, PSU Human Resources

\section{Communication}

Communication is at the heart of all of these recommendations, but deserves its own section as well. Without communication improving culture is nearly if not entirely mpossible, and lack of consistent communication seems to be one of the common woes at PSU.

a. Two-way communication with staff

Keeping staff informed is a very important component of engagement ${ }^{34}$. Communication must also be two-way. Hearing feedback from employees about how they work best or when they report discrimination is useless without a response and follow-through to make improvements and address issues (which can significantly impact trust). communicate about what is going on in the department and on campus proactively; simply having an "open door policy" is not enough and puts the responsibility on staff far too much. Inviting staff to exit interviews consistently cas may have bing for hearing about issues that employto hear posie been uncomfortable and is an opportunity taken seriously; the rtunities for change that should be constructive feed hat requires managers who are open to they need to be successful, and take their feede what ously, especially when it involues feeling underack serdiscriminated against Staff will not feel comfortable reporting issues or giving honest feedback if a culture that alues honest communication is not present 
Creating a culture that values and encourages honest feedback and communication relies heavily on that culture of inclusion. If staff feel like their supervisors or coworkers will not actually listen to them, they will become rect assumptions as well. To and likely operate on incormust provide, know how to hear, and value honest feed back. Information must be communicated proactively in a way that employees want to hear. Staff absolutely must feel safe reporting issues (especially sensitive ones like discrimination ${ }^{33}$ ) to leadership and believe that something will be done about it, or a toxic culture of silence will take hold. The more managers and employees can model and hold each other accountable to positive communicatio practices (e.g. Crucial/Fierce Conversations principles, having complicated discussions in person versus email explaining "why" and not just "how, and many more), the more this culture will become a part of PSU.

\section{Relationships}

Silo'ing is a problem with any large organization, and PSU is certainly no exception. Relationship building is not jus for social pleasure - it creates empathy, engagement, an are important to would not otherwise exist. Relationships relationships and networks, however, are also very benefcial for the organization; the collective energy formed from networks and relationships adds an incredible amount of benefit to PSU. Workplace relationships are more important than rewards, and positive relationships with coworkers can improve emotional, physical, and cognitive well-being, increase organizational commitment and innovation, and essential to high performers

\section{"SLOW DOWN, GET TO KNOW}

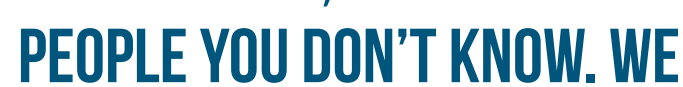

.

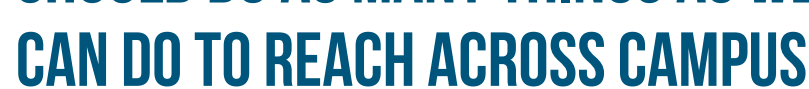

AND BRING PEOPLE TOGETHER."

DR. ISAAC DIXON, PSU HUMAN RESOURCES a. Encourage relationship-building

All the programs in the world could exist, but there will be low participation if no one knows about them, if managers do not allow time to attend, or if staff feel any time active communication of groups and events must come alongside an understanding of the value they bring. Relationships are vital to a functioning organization, and PSU cannot be as successful if departments remain in silos. Inform and encourage events like volunteering to not just connect to the students and community served, but as an opportunity to connect with colleagues.

If you don't know someone, it's easy

to pass judgement on who they are

sona Andrews, PSU Academic Affairs

Provide the time and relief from work duties to attend campus-wide events like convocation, Length of Service awards, or Celebrate the Season. Plan events that are no just social, but include working together towards a comatherings like employees know about any community may not necessarily happen on work time but that can construct relationships with others in the community: this can be particularly valuable for marginalized populations with low representation at PSU or in Portland. Create team retreats that are a mix of strategy, problem-solving and relationship-building (including encouraging vulnerability which strengthens connections). Instead of sending long emails back and forth, demonstrate to colleagues the value of picking up the phone or setting up a time to talk to someone in person about difficult topics.

The more empathy and understanding that can be created between people through forging those personal relationships across the university, the more effective the organization will be and less likely to blame, shut down, and silo up. These relationships cannot be formed when managers or leadership have a combative "us vs. them" mentality, micromanage their employees' time sitting a their desks, or fail to provide the opportunity to engage with others across the university. The benefit gained from these events and not spent responding to mar year a forming other transactional job duties. b. Build relationships for future students and employees

Relationships aren't just for current colleagues or students. By getting to know others in the community, PSU employees can learn from other organizations or deveop their network of possible future talent for open positions. Creating partnerships with community groups or $k-12$ schools, particularly those in underserved areas who can have a harder time accessing education, can build the pipeline for future students, student leaders, employees, and leadership.

“Address the pipeline problem by creating more partnerships with schools in specific areas, get more kids in high school knowledgable and interested in possible opportunities, internships, shadowing, et cetera.

$$
\text { Eric Weeks, Legacy Medical Group }
$$

c. Invest in programs

Investing resources (including time and the energy to organize) in specific groups or programs is an excellent way to lead by example and show employees that relationships are valued and valuable. CSUSM's Campus Connect program openly focuses on has been highly successful at creating relationships spanning all types of employees, including faculty, academic administrators, and front-line staff. Employee Resource Groups (also known as Affinity Groups) can promote relationships, leadership and development, support, and inclusion. These are not just social interaction, but can be a think-tank and very real source of progress for an organization ${ }^{64}$. Resource groups are an excellent way to bring marginalized groups together across the university to create camaraderie and decrease the sense of "only-ness" that can so often happen in spaces with large dominant groups or low diversity. PSU has fairly new resource groups, but should focus on working with them more, empowering them to work together to make

\section{Actual work}

xaming the work itself provides an opportunity to relieve employee stress and increase engagement. In order to do this, someone must ask employees what their barriers are, then remove them ${ }^{11,6}$, which has been a successful tactic with multiple departments at PSU. Involve employees in and take a step back and seriously consider eliminating certain tasks that fail to align with to the departmental or university mission. This will free employees up to do more interesting work that is the right amount of challenging ${ }^{10,51}$ ("flow") and show that managers actually care about their work experiences. Matching skill with mission is a crucial component of engagement ${ }^{2}$, and it is demotivating to be continually spending time on boring or frustrating work that is too easy (e.g. repetitive tasks like data entry) or too hard instead of using interesting and useful skills to drive PSU's success. If the type of work is unevenly distributed, e.g. certain marginalized populations more frequently being assigned or taking on less desirable tasks or taking on more of the workload, this will create more dispara

"Be mindful to assign work so it takes advantage of people's' strengths. If you have an employee who isn't particularly strong in one area, ask "is there something else they could be doing that they're strong at" instead of beating them over the head with something they'll never be good at This creates engagement because you have folks working on what they feel most capable doing."

Illen Weeks, PSU Office of Information Technology 
“I'VE FOUND PROBLEMS BUILD AT A

UNIVERSITY BECAUSE PEOPLE SEND

EMAILS AND DO NOT GET TOGETHER

IN A ROOM AND TALK THROUGH THE

ISSUE. YOU ALSO HAVE TO LISTEN

TO UNDERSTAND WHERE THE OTHER

PERSON IS COMING FROM. PART

OF CREATING A MORE ENGAGED

WORKFORCE IS TO HAVE MORE TIME

SPENT FACE TO FACE WITH PEOPLE;

TURN OFF THE WIFI, PUT DOWN THE

SMART PHONE."

DR. KEVIN REYNOLDS, PSU FINANCE AND ADMINISTRATION

CHAPTER

5

SUMMARY

1. Key Insights

2. Limitations

a. Humans are complicated

b. Limited data

c. Subcultures create nuance

d. Limited resources and prioritization

3. Next Steps

a. What to do

4. Closing 


\section{Key Insights}

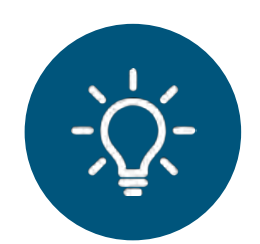

Being a member of a marginalized group affects many workplace experiences, including engagement. These groups are often faced with overt and tional taxation both in and outside of work.

Managers have the greatest effect on engagemen and an inclusive culture, but are not always aware disengagement and inequity Alt hevels of PSU lin ership must value and invest in manager training.

Culture happens no matter what. PSU must be intentional about what it encourages, both as a whole and within departments. This requires carefully selecting leaders, cohesive communication, and buy-in that stems from understanding

An inclusive, employee-centered culture is an investment that will pay off in many ways. However, it is a new concept for many areas and requires time and resources, along with a collaborative and synchronized effort. This requires ownership.

For the most part, managers and employees want engagement, effective performance, connection to purpose, and equitable treatment - but need help. be used to propel PSU's excellence even further.

\section{Limitations}

Humans are complicated

Engagement and equity are complicated issues that cannot be easily understood or solved. Understanding of the human mind and why people act the way they do is an ever-growing field, but still much is left to the unknown. While we can make assumptions and generalizations about why underrepresented groups may be having certain experiences, it is difficult to understand, and experiences vary widely. Generalizations, while they can help to understand broad causes and effects, also come with the risk of stereotyping. There is no one right and certainly no simple solution for PSU. Many people belong to more than one marginalized group, and this intersectionality can provide even more factors to their experiences. Everyone has their own story, and non-marginalized groups should not be stereotyped or ignored.

\section{b. Limited data}

Access to the full Gallup Q12 data would have led to more statistically significant results. If PSU is serious about wanting to understand how different people are affected by their intrinsic qualities, it should invest in the data to do a proper analysis. Furthermore, expanding the survey to more of PSU would be very beneficial - not only to get a better understanding of engagement across departments, but to include more marginalized populations in the data (e.g. very few non-white participants means the data for those ethnicities is difficult to generalize). The low numbers for some groups (e.g. Native American or Transgendered) render ever

\section{c. Subcultures create nuance}

While a campus-wide survey would give some insights, there are also many nuances between departments due to leadership. Furthermore, being a woman in technology vs human resources, for example, will greatly change the equity subcultures for MPs. Understanding and communicating all of these differences and subcultures at PSU is a colossal task that may not even be possible to realize, but does leave this report resting on generalizations.

\section{d. Limited resources and prioritization}

con perfect world, PSU would be able to invest in many programs and positions. These recommendations are in direct competition with many others that will also support education and the mission of PSU. However, the university must understand that investing in people (all people) is essential for excellence.

“University engagement needs to come from a president who cares about the employees.

Kirk Kelly, PSU Information Technology 


\section{Next Steps}

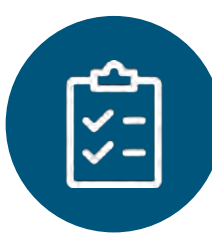

a. What to do

The above "Recommendations" section is very large; here are a few recommendations for where to start:

Start an employee-led engagement effort or task force that includes a variety of employees, with leadership buy-in to focus on research and recommendations. Employee feedback is essential for equitable treatment and engagement Identify a campus "champion" of engagement and culture who has ownership, backing by PSU leadership (including the president), time to dedicate on leading these efforts, an understanding of equity issues, and a close partne ship with OCDl and HR. Cu dure change is a collaborative and an unsive effort

(CSUSM, OSU, UO, UBC) about how they CSUSM's Campus Con

(n) Gallup survey (or other engagement survey), investing in the the demographic information collected, measuring the results, nd creating benchmarks.

Leadership/management training is essential; for example, managers don't necessarily know how to hire for Pubaround communicating thitate an inclusive culture, or create a trusting environment. Someone must have ownership wards a more consistent employee experience across areas

" Establish a Search Advocate Program (done!) and require all searches to go through some sort of inclusion training or include a Search Advocate in the process. Inclusive hiring is very complicated, but must be addressed.

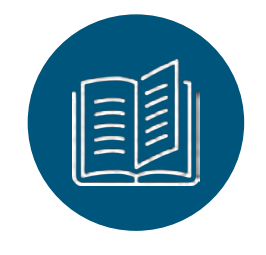

b. What to read

All of the works cited were very interesting and often inspiring - but it's also a lot of information. Below are a few good places to start for PSU, particularly administration but also to disseminate to department managers:

"To better understand how important Public Service Motivation is for engagement, see Bakker's article" about engagement and job demands (or even just Lavigna's summary ${ }^{10}$.

For information on building a trusting culture, see both Harvard Business Review articles on trust, "The Neuroscience of Trust t" $^{\text {" }}$ and "Want Your Employees to Trust You? Show You Trust Them ${ }^{\text {54" }}$.

Read about organizations who have successfully created a more engaging culture through inclusion, particularly Project Include ${ }^{27}$ and tactics by Google ${ }^{32},{\mathrm{~B} \& Q^{8}}^{8}$ and Atlassian ${ }^{22}$

Read the “Lessons in Leadership: The IDeA and Ipsos MORI's Latest Research on the Links between Leadership and .

(S) Minorities Perform Worse Under Enthicity and Employee Engagement on Withdrawal Beavioris".

For evidence that employee perceptions do impact the bottom line (including finances and customer satisfaction), see Harter et al's "Causal Impact of Employee Work Perceptions on the Bottom Line of Organizations".

\section{Closing}

Engagement and equality are fairly popular topics with lots of research, which is both very fortunate and very overwhelming in terms of distilling down information. Less exists about engagement through the equity lens or differences in how those who belong to marginalized groups may be differently affected due to their group membership or intrinsic traits. Overall, PSU should better focus on its employee experience and the culture it fosters around valuing engagement, and do it all through the lens of inclusion. This report has identifed some recommendations that would help psu's employee engagement for all employees, but specifically for those who may be experiencing less of it due to their status. If PSU wants to harness the benefits of engaged employees, diversity, and an inclusive culture, it must prioritize and invest in its people. Employee engagement isn't a ping pong table or short-term program to make employees happy. It's a culture that values, empowers, and supports *all* employees so they can be successful.

"PUT PEOPLE AT THE HEART OF

BUILDING THE INSTITUTION."

SUKHWANT JHAJ, PSU ACADEMIC INNOVATION 


\section{REFERENCES}

[1] Harter, James K., et al. "Causal Impact of Employee Work Perceptions on the Bottom Line of Organizations." Pers
Psychological Science, vol. 5, no. 4, 2010, pp. 378-389.

[2] Jones, James R., and James K. Harter. "Race Effects on the Employee Engagement-Turnover Intention Relationship." Journal of [3] Morgan, Jacob. The Employee Experience Advantage: How to Win the War for Talent by Giving Employees the Workspaces They Want, the Tools they Need, and a Culture They Can Celebrate. W.

[4] Bakker, Arnold B. "A Job Demands-Resources Approach to Public Service Motivation. Public Administration Review, Edited by HaI G. Rainey, vol. 75, no. 5, 2015, pp. 723-732.

[5] Macleod, David, and Nita Clarke. "Engaging for Success: Enhancing Performance Through Employee Engagement: A Report to Government. UK Department for Business, Innovation, and Shlls, 2009. Metp.//webarchive.nationalarenives.gov. [e] [6] Rivera, Aurelio "PJ", and Jacob Flinck. "Employee-Led, Employee
Engagement in the Federal Government", Advances in Developing Engagement in the Federal Government." Advances in
Human Resources, vol. 13, no. 4, 2011, pp. 479-493.

[7] Larkin, Jim. "IPMA-HR Study Sheds Light On U.S. Public Sector Employee Engagement." PR Newswire, ADP, 11 Sept. 2012 http:// www.prnewswire.com/hews-releases/adp-and-ipmahr-study-sheds-light-on-us-public-sector-employee-engage-

[8] Pollitt, David. "Employee engagement "does it" for B\&Q: Diversity at the heart of business suctess", Human Resource Manger

[9] Logan, Debra, Carol Rozwell. "Diversity's Role in an Effective Digital Workplace Program." 'Gartner, Inc. 30 March 2016, ID:

[10] Pink, Daniel H. Drive: the Surprising Truth about What Motivates Us. Riverhead Books, 2012.

[11] Moody, Vernice J. "Examining Leadership Styles and Employee Engagement in
Phoenix, 2012.

[12] Partnership for Public Service and Deloitte. "The Best Places to Work in the Federal Government: 2016 Rankings." Bestplaces towork.org, Dec 2016, http: / / 1yxsm73j7aop3quccyysifaw3-wpengine. netdna-ssl.com/wp-content/uploads/2016/12/BPTW16_Brochure. pdf. clusion And Diversity." Fast Company, 12 Sept. 2013, www.fastcompany.com/3016763/uncovering-talent-a-new-model-for-inclusion-and-diversity.

[26] First Round "Atlassian Boosted Its Female Technical Hires By 80\% - Here's How." First Round Review, 6 July 2017, http:// firstround.com/review/atlassian-boosted-its-female-technicahires-by-80-percent-heres-how

[27] http.//projectinclude ors

[28] Jost, John T., et al. "The Existence of Implicit Bias is beyond Reasonable Doubt: A Refutation of Ideological and Methodolo Manager Should Ignore. 29, 8 Nov. 2009, pp. 39-69.

[29] Price, Joseph, and Justin Wolfers. "Racial Discrimination Among NBA Referees" The Quarterly Journat of Economics, Nou. 2010, pp. 1859-1887.

[30] McMurtrie, Beth. "How to Do a Better Job of Searching for Diversity." The Chronicle of Higher Education, 11 Sept. 2016, wh How-to-Do-a-Better-Job-of/237750.

[31] Greenberg, Margaret H., and Dana Arakawa. "Optimistic Managers \& Their Influence on Productivity \& Employee Engageme plied Positive Psychology (MAPP) Capstone Projects, 10 Oct. 2006 [32] Fessler, Leah. "Google Is Sharing Its Management Tools with [32] Fessler, Leah. "Google Is Sharing Its Management Tools with
the World." Quartz, 21 Aug. 2017, http:// qz.com/1058563/these-aregoogles-tools-for-effective-management/.

[33] https:/ / www.csusm.edu/campusclimate/index.html

[34] Page, Ben, and Martin Hornton. "Lessons in Leadership: The IDeA and IPsos MORI's Latest Research on the Links between Leadership and Management Style and Performance in Local Gorernment. " apsos, Improvent \& Development Agency, www.lpsos

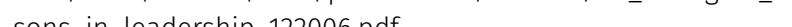

[35] Kelly, Kirk R., and Brenna D. Kutch. "From Climbing Walls to Culture of Caring." Educause, 28 Aug. 2017, http:/ / er.educause.e

[36] https:// /www.csusm.edu/president/initiatives/

[37] http:// www.csusm.edu/campusconnect/

[38] Cross, Rob, et al. "Building Engagement from the Ground up How Top Organizations Leverage Networks to Drive Employee En-

[39] https:// teibelinc.com/podcast/173

[40] Crowley, Mark C. "6 Surprising Insights Of Successful Employee Engagement. Fast Company, 16 July 2015, www.fastcompancom/3048503/6-

[41] Risher, Howard. "Performance Management Needs to Be
[42] https://www.csusm.edu/president/documents/2014/strategicplan_march2014.pdf

[43] http://wmm hrubcca/learning-engagement/strategic-priori-

44] Murphy, Mark A. Hiring for Attitude: a Revolutionary Approach Recruiting Star Performers with Both Tremendous Skills and Superb Attitude. McGraw Hill Education, 2017.

45] Bock, Laszlo. "Here's Google's Secret to Hiring the Best People" 6 June 2017, http://www.wired.com/2015/04/

[46] Lavigna, Robert J. "Innovation in Recruiting and Hiring: AtPracting the Best and Brightest to Wisconsin State Governmente

[47] Maurer, Roy. Onboarding Key to Retaining, Engaging Talent. Society for Human Resources Management, 30 June 2017, www. shrm.org/resourcesandtools/hr-topics/talent-acc is

[48] http://www.partnersindiversity.org/programs/say-hey.html

49] Diversity Action Council Annual Report (personally obtained) https://drive.google.com/file/d/0B8cxtteKmvflNGXURUswRozC$\mathrm{uUO/}$

[50] DAC Recruitment and Retention of Diverse Staff Subcommitlee: Report 2016-17 (personally obtained), https://docs.google. com/document/d/7MK1xV7Ca2tNhKme-UBgWVMTSUcinipscfuAefPHfLhol

[51] Zak, Paul J. "The Neuroscience of Trust." Harvard Business Review, ence-of-trust.

52] DelCampo, Robert G., et al. "Psychological Contract Breach, Perceived Discrimination, and Ethnic Identification in Hispanic 2, 2010, pp. 220-238.

[53] Wilson, David C. "When Equal Opportunity Knocks." Gallup, Inc., 13 Apr. 2006, http://news.gallup.co
when-equal-opportunity-knocks.aspx

[54] Brower, Holly Henderson, et al "Want Your Employees to Trust You? Show You Trust Them."Harvard Business Review, 11 In Trust 2017 http://hbrorg/2017/07/want-your-employees-to-trust-you-showyou-trust-them.

[55] Ryan, Richard M., and Edward L. Deci. "Self-Determination Theory and the Facilitation of Intrinsic Motivation, Social Developpp. 68-78.

[56] Gagné, Marylène, and Edward L. Deci. “Self Determination urnal of Organizational Behavior, John Wiley \& Sons, Ltd., 14 Apr. 2005.

[57] Gligorea, Ramona. "Authentizotic Organizations - the Solution for Low Engagement Levels." Performance Magazine, 22 May tions-the-solution-for-low-engagemenent-levels/. 
[59] McLeod, Lisa Earle. “Why Millennials Keep Dumping You: An Open Letter to Management."Linkedin, 3 Oct. 2015, http:// www. linkedin.com/pulse/why-millennials-keep-dumping-you-openletter-lisa-earle-mcleod.

[60] Bernier, Brandon, and Jaclyn Zavoral. "The BenefiT of Workforce Development." Eaucause, 24 Apr. 2017, http.//er.educause edu/blogs/2017/4/the-benefit-of-workforce-development.

61- Olenski, Steve. "8 Key Tactics For Developing Employees" Forbes Magazine, 20 July 2015, www.forbes.com/sites/steveolenski/2015/07/20/8-key-tactics-for-developing-employees.

[62] Dishman, Lydia. "Why Having Friends At Work Is So Important." Fast Company, 25 May 2016, www.fastcompany.com/3051290/whyhaving-friends-at-work-is-so-important.

[63] Diversity Primer, Chapter 10. Diversity Best Practices, 2009 [63] Diversity Pimer, Chapter 10. Diversity Best Pracic

[64] Llopis, Glenn. "7 Ways to Enable Your Employee Resource Groups into a Powertul Advancenent/sites/gennllopis/2012/06/18/7-ways-to-enable-your-employee-resource-groups-into-a-powerful-advancement-platform.

[65] Gallup, Inc. "Strengthening Your Company's Performance. 2011, http://news gallun com/businessjournal/146351/Strengthening-Company-Performance.aspx.

[66] Gallup, Inc. "The Secret of Higher Performance." Gallup.com

Epilogue

\section{APPENDICES}

A. Civil Rights in Oregon

B. Interviews

C. Engagement Survey of MPs

1. Survey overview

D. CSUSM Campus Connect Information Packet Snippet 2015-16 


\section{Appendix A. Civil Rights Timeline in Oregon}

Oregon has a slightly different civil rights timeline than federal laws, though it also has a sordid past with racism that

\begin{tabular}{|c|c|c|}
\hline Protection & When in Oregon & When Federal \\
\hline Women allowed to vote & 1920 & 1920 (Nineteenth Amendment) \\
\hline Native Americans eligible to be citizens & - & 1924 \\
\hline Racial discrimination in voting prohobited & 1927 & 1869 (Fifteenth Amendment) \\
\hline $\begin{array}{l}\text { Employment discrimination based on union } \\
\text { affiliation prohibited }\end{array}$ & - & 1935 (National Labor Relations Act) \\
\hline Ban on Japanese living on the Pacific Coast lifted & - & 1944 \\
\hline Ban on interracial marriage lifted & 1951 & 1967 \\
\hline Racial segregation in public places prohibited & 1953 & 1964 (Civil Rights Act of 1964) \\
\hline Disability discrimination in hiring prohibited & 1953 & 1990 \\
\hline All races eligibile for US naturalization & - & 1952 (Immigration and Nationality Act) \\
\hline Racial segregation in public schools prohibited & - & 1954 (Brown v. Board of Education) \\
\hline $\begin{array}{l}\text { Wage discrimination based on sex and race } \\
\text { prohibited }\end{array}$ & $\begin{array}{l}1955 \text { (Oregon's Equal } \\
\text { Pay Act) }\end{array}$ & 1973 (Equal Pay Act) \\
\hline Racial discrimination in housing prohibited & $\begin{array}{l}1957 \text { (Oregon Fair } \\
\text { Housing Act) }\end{array}$ & $\begin{array}{l}1968 \text { (Civil Rights Act of 1968, including } \\
\text { Fair Housing Act) }\end{array}$ \\
\hline $\begin{array}{l}\text { Broad discrimination based on race, color, religion, } \\
\text { sex, or national origin in public places, schools, } \\
\text { and employment prohibited }\end{array}$ & - & 1964 (Civil Rights Act of 1964) \\
\hline Racial discrimination in hiring prohibited & - & 1964 (Civil Rights Act of 1964) \\
\hline $\begin{array}{l}\text { Criminal history discrimination in employment } \\
\text { prohibited }\end{array}$ & - & 1964 (Civil Rights Act of 1964) \\
\hline $\begin{array}{l}\text { Prerequesites/qualifications for voting (e.g. literacy } \\
\text { tests) prohibited }\end{array}$ & - & 1965 (Voting Rights Act) \\
\hline Age discrimination in employment prohibited & - & 1967 (Age Discrimination in Employment \\
\hline Sexual harassment at work prohibited & - & 1968 \\
\hline Abortion decriminalized & 1969 & 1973 \\
\hline $\begin{array}{l}\text { Sex discrimination in federally-funded education } \\
\text { prohibited }\end{array}$ & - & $\begin{array}{l}1972 \text { (Title IX of the Education } \\
\text { Amendments Act) }\end{array}$ \\
\hline Homosexuality decriminalized & 1972 & 2003 \\
\hline Unmarried persons ban on contraceptives lifted & - & 1972 \\
\hline Sex discrimination in housing prohibited & - & 1974 \\
\hline
\end{tabular}

\begin{tabular}{|l|l|l|}
\hline Schools required to serve students with disabilities & - & $\begin{array}{l}1975 \text { ("Education for All Handicapped } \\
\text { Children Act" renamed to "Individuals } \\
\text { with Disabilities Education Act" in 1990) }\end{array}$ \\
\hline $\begin{array}{l}\text { Community college esteablished on every Native } \\
\text { Ameican reservation }\end{array}$ & - & $\begin{array}{l}1978 \text { (Tribally Controlled Community } \\
\text { College Assistance Act) }\end{array}$ \\
\hline $\begin{array}{l}\text { Pregnancy discrimination in employment } \\
\text { prohibited }\end{array}$ & 1978 (Pregnancy Discrimination Act) \\
\hline Marital immunity for rape & 1978 & $\begin{array}{l}\text { No federal law (but illegal in all 50 states } \\
\text { in varying permutations as of 1993) }\end{array}$ \\
\hline $\begin{array}{l}\text { Native Americans allowed to fully believe, express, } \\
\text { and exercise traditional religious rights and } \\
\text { cultural practices }\end{array}$ & - & $\begin{array}{l}1978 \text { (American Indian Religious Freedom } \\
\text { Act) }\end{array}$ \\
\hline Desegregation busing outlawed & No federal law \\
\hline Same-sex sexual harassment at work prohibited & - & 1998 \\
\hline $\begin{array}{l}\text { Forced/coerced sterilization (e.g. mental hospitals, } \\
\text { prisoners) prohibited }\end{array}$ & 1983 & No federal law \\
\hline $\begin{array}{l}\text { Sexual orientation discrimination in hiring } \\
\text { prohibited }\end{array}$ & 1992 & ??? \\
\hline Conversion therapy on minors prohibited & 2003 & No federal law \\
\hline Gender identity discrimination in hiring prohibited & 2007 & 2012 \\
\hline Ban on same-sex marriage lifted & 2014 & 2015 \\
\hline $\begin{array}{l}\text { Background checks prohibited before offer made to } \\
\text { decrease impact on felons }\end{array}$ & 2015 ("Ban the Box" & No federal law \\
\hline $\begin{array}{l}\text { Gender identity discrimination in federally-funded } \\
\text { education, e.g. rights for trans students }\end{array}$ & 2016 & ??? \\
\hline $\begin{array}{l}\text { Asking for candidate wage history in the hiring } \\
\text { process prohibited }\end{array}$ & $\begin{array}{l}2017 \text { (Oregon Pay } \\
\text { Equity Law) }\end{array}$ & No federal law \\
\hline
\end{tabular}

Sources

City of Portland Office of Equity and Human Rights: https:// www.portlandoregon.gov/oehr/66269

City of Portland's Timeline of Oregon and U.S. Racial, Immigration and Education History: https://www.portlandoregon.gov/bps/article/412697

Oregon Encyclopedia - Exclusion Laws: https:// /oregonencyclopedia.org/articles/exclusion_laws/

Oregon Council on Civil Rights - Pay Inequality in Oregon: http:// www.oregon.gov/boli/docs/Pay\%20Inequality\%200regon\%20

012314-Final.pdf

Oregon Dept of Education - Oregon Racial Laws: http://www.ode.state.or.us/opportunities/grants/saelp/orraciallaws.pdf 


\begin{tabular}{|c|c|c|c|}
\hline Date & Name & Title & Organization \\
\hline $5 / 16 / 2017$ & Sarah Johnston & $\begin{array}{l}\text { Senior HR Consultant, Organizational } \\
\text { Development \& Strategy }\end{array}$ & Portland State University \\
\hline $5 / 18 / 2017$ & Lois Davis & Vice President for Public Affairs and Chief of Staff & Portland State University \\
\hline $5 / 30 / 2017$ & Susan Klees & Special Assistant to the Vice President & Portland State University \\
\hline 6/19/2017 & Dr. Carmen Suarez & Vice President, Global Diversity and Inclusion & Portland State University \\
\hline 6/26/2017 & Dr. Sona Andrews & Provost & Portland State University \\
\hline 6/27/2017 & Kirk Kelly & $\begin{array}{l}\text { Associate Vice President, Information Technology; } \\
\text { Chief Information Officer }\end{array}$ & Portland State University \\
\hline 7/17/2017 & Dr. Karen Marrongelle & Dean, College of Liberal Arts and Sciences & Portland State University \\
\hline 7/20/2017 & Dr. Masami Nishishiba & $\begin{array}{l}\text { Chair, Department of Public Administration; } \\
\text { Associate Director, Center for Public Service }\end{array}$ & Portland State University \\
\hline 7/24/2017 & Ellen Weeks & Associate CIO, Information Technology & Portland State University \\
\hline 7/24/2017 & Sukhwant Jhaj & $\begin{array}{l}\text { Vice Provost, Academic Innovation and Student } \\
\text { Success }\end{array}$ & Portland State University \\
\hline 7/25/2017 & Eric Weeks & Vice President & Legacy Medical Group \\
\hline $8 / 1 / 2017$ & Kassy Fisher & $\begin{array}{l}\text { Assistant Vice President, Administration; Chief of } \\
\text { Staff }\end{array}$ & University of Oregon \\
\hline $8 / 3 / 2017$ & Anne Gillies & Director, Search Advocate Program & Oregon State University \\
\hline 8/31/2017 & $\begin{array}{l}\text { Jennifer Williams } \\
\text { Katy Rees }\end{array}$ & $\begin{array}{l}\text { Associate Vice President, Campus Climate; Chief } \\
\text { of Staff } \\
\text { Associate Vice President, Finance and } \\
\text { Administrative Services }\end{array}$ & $\begin{array}{l}\text { California State University: San } \\
\text { Marcos }\end{array}$ \\
\hline 10/9/2017 & Dr. Isaac Dixon & Associate Vice President, Human Resources & Portland State University \\
\hline 10/13/2017 & Dr. Kevin Reynolds & Vice President, Finance and Administration & Portland State University \\
\hline
\end{tabular}

\section{Survey overview}

\begin{tabular}{|c|l|}
\hline$\#$ & Questions \\
\hline 1 & Are you a PSU employee? \\
\hline 2 & In general, how engaged are you at your job? \\
\hline 3 & With which marginalized group(s) do you identify? \\
\hline 4 & $\begin{array}{l}\text { Do you feel that being a member of this/these group(s) has affected your employee engagement (positively or } \\
\text { negatively), and if so, how? }\end{array}$ \\
\hline 5 & How respected do you feel for your differences by your manager? \\
\hline 6 & How respected do you feel for your differences by your coworkers? \\
\hline 7 & How comfortable do you feel speaking up against the status quo to your manager? \\
\hline 8 & How comfortable do you feel speaking up against the status quo to your coworkers? \\
\hline 9 & $\begin{array}{l}\text { How do you think being respected for your differences and feeling comfortable being different affect your personal } \\
\text { employee engagement? }\end{array}$ \\
\hline 10 & What could PSU/your organization do to increase your engagement? \\
\hline 11 & Do you have any additional thoughts about this subject that you haven't had an opportunity to voice elsewhere? \\
\hline
\end{tabular}

Anonymized survey results available upon reques

\begin{tabular}{|c|c|}
\hline \multicolumn{2}{|l|}{ Respondants and numbers on a 1-10 scale } \\
\hline Total respondants & 25 \\
\hline Total who were PSU employees & 18 \\
\hline Self-identified engagement & Low 5 , High 10; Average 7.4 \\
\hline Respected for differences by manager & Low 1, High 10; Average 7.3 \\
\hline Range of respected for differences by coworker & Low 4, High 10; Average 7.3 \\
\hline Range of comfort speaking against the status quo to manager & Low 1, High 10; Average 7.1 \\
\hline Range of comfort speaking against the status quo to coworkers & Low 3, High 10; Average 6.7 \\
\hline Marginalized groups represented & $\begin{array}{l}\text { Women, queer, trans, nonbinary, people of color, age, differently } \\
\text { abled, ND }\end{array}$ \\
\hline
\end{tabular}


Appendix C. Engagement Survey of Marginalized Populations

\section{Data Analysis}

\begin{tabular}{|c|c|c|c|c|c|}
\hline & engaged & respected $\mathrm{mgr}$ & respected cwkrs & status quo $\mathrm{mgr}$ & status quo cwkrs \\
\hline engaged & 1.0 & - & - & - & - \\
\hline respected by mgr & $.519^{\star \star}$ & 1.0 & - & - & - \\
\hline respected by coworkers & $.410^{*}$ & $.575^{\star \star}$ & 1.0 & - & - \\
\hline status quo mgr & $.535^{\star \star}$ & $.799^{\star *}$ & $.680^{\star \star}$ & 1.0 & - \\
\hline status quo coworkers & $.546^{* \star}$ & $.512^{\star \star}$ & $.657^{* \star}$ & $.776^{* *}$ & 1.0 \\
\hline
\end{tabular}

** - correlation significant at 0.01 level

* - correlation significant at 0.05 level

\section{Appendix D. CSUSM Campus Connect Information 2015-16 Packet Snippet}

Campus Connect

\section{WELCOME TO CAMPUS CONNECT 2016}

Welcome to the Campus Connect Program for 2016 ! Campus Connect is a 9-month, awareness enhancing program that showcases the inner-workings of the university so that participants will better understand and appreciate the connections between our divisions and departments.

\section{Requirements \& Expectations:}

1. Commit.

Campus Connect is a true commitment of time. The sessions are full and we move quickly to cover as much information as possible in a short period of time. We ask that you attend all sessions, but we do understand if there are circumstances outside of your control, so here is the fine print:

You may miss up to two sessions.

Each session runs from 12 noon - 4:30 pm each day, with the exception of Orientation Day.

> If you arrive after noon or leave prior to 4:30 pm, you will be marked as absent and it will count as a missed session.

D If you miss more than two sessions, you will not graduate from the program.

2. Engage.

Our goal is for you to completely step away for four hours and immerse yourself in this valuable program. Each facilitator presentations are engaging and fun. A lot of work goes into Campus Connect, so we ask that you please silence your cell phones and do not utilize during the class presentations. You may use your cell phones during breaks or if there are interactive games, which require the use of devices, but we kindly request you keep your cell phones stored during the sessions.

3. Connect.

While Campus Connect provides you with the opportunity to learn about other departments and divisions, it also provides you with the opportunity to connect with your classmates. Use the lunches and breaks to network and get to know one another. Don't sit in the same spot or next to the same person for each session - get to know all of your colleagues and it will give you the richest experience possible. Incredible friendships and partnerships have been built during Campus Connect and continue on over the years.

4. Graduate.

Upon graduation, we welcome you into the Campus Connect Ambassadorial Network. You will join over 200 of your colleagues and be part of a unique group. Each year, you will be welcomed back together to take part in the annual Alumni Lunch \& Celebration. 
Campus Connect Awakens

2015/16 Class Schedule

\begin{tabular}{|c|c|c|c|}
\hline Date & Time & Theme & Facilitators \\
\hline August 18, 2015 & $\begin{array}{l}\text { 1:00- } \\
\text { 4:00 p.m. }\end{array}$ & $\begin{array}{l}\text { Campus Connect Orientation } \\
\text { Orientation and history of Campus Connect }\end{array}$ & Orientation Team \\
\hline September 4, 2015 & $\begin{array}{l}\text { Noon- } \\
\text { 4:30 p.m. }\end{array}$ & $\begin{array}{l}\text { "The Campus Awakens" } \\
\text { Overarching View: President, CSU and CO, Senate/Shared } \\
\text { Governance, Founding Members }\end{array}$ & $\begin{array}{l}\text { Adrienne Durso } \\
\text { Bhavisha Talsania }\end{array}$ \\
\hline October 2, 2015 & $\begin{array}{l}\text { Noon- } \\
4: 30 \text { p.m. }\end{array}$ & $\begin{array}{l}\text { "The Galactic Empire" } \\
\text { Global View: Executive Council, IITS, Enrollment Management } \\
\text { Services, Facility Services, University Police }\end{array}$ & \begin{tabular}{|l} 
Becky Hunt \\
Scott Kirby
\end{tabular} \\
\hline November 6, 2015 & $\begin{array}{l}\text { Noon- } \\
\text { 4:30 p.m. }\end{array}$ & $\begin{array}{l}\text { "A Galaxy not too far Away" } \\
\text { View to the Outside (and a peek underground): Extended } \\
\text { Learning, International Students and Global Education, } \\
\text { UARSC, Athletics, Tunnel Tour/Power Plant }\end{array}$ & $\begin{array}{l}\text { Floyd Dudley } \\
\text { Clint Roberts } \\
\text { Travis Gregory }\end{array}$ \\
\hline December 11, 2015 & $\begin{array}{l}\text { Noon- } \\
\text { 4:30 p.m. }\end{array}$ & $\begin{array}{l}\text { “The Jedi Academy” } \\
\text { Academics: CHABSS, CSM, COBA, CEHHS, Library, Life of a } \\
\text { Faculty }\end{array}$ & $\begin{array}{l}\text { Kamel Haddad } \\
\text { Jen Fabbi } \\
\text { Manuel Vargas }\end{array}$ \\
\hline January 15, 2016 & $\begin{array}{l}\text { Noon- } \\
\text { 4:30 p.m. }\end{array}$ & $\begin{array}{l}\text { "Sir, the odds of successfully navigating an asteroid field is } \\
\text { approximately 3,720 to 1" "Never tell me the odds." } \\
\text { The Research Side: Graduate Studies, Centers \& Institutes, } \\
\text { Faculty/Student Research, Lab Tours }\end{array}$ & $\begin{array}{l}\text { Sean Newcomer } \\
\text { Jay Robertson-Howell } \\
\text { Jocelyn Wyndham }\end{array}$ \\
\hline February 12, 2016 & $\begin{array}{l}\text { Noon- } \\
\text { 4:30 p.m. }\end{array}$ & $\begin{array}{l}\text { "Obi Wan has taught you well" } \\
\text { Academic and Student Services: Undergraduate Studies, } \\
\text { Student Academic Support Services, Academic Advising, } \\
\text { Academic Life of a Student, City of San Marcos }\end{array}$ & $\begin{array}{l}\text { Domenica Pearl } \\
\text { Maya Alvarez } \\
\text { Scott Hagg }\end{array}$ \\
\hline March 11, 2016 & $\begin{array}{l}\text { Noon - } \\
\text { 4:30 p.m. }\end{array}$ & $\begin{array}{l}\text { "The force is strong with this one" } \\
\text { Student Life: Dean of Students, ASI, USU, Housing, Financial } \\
\text { Aid, Student Health \& Counseling Services }\end{array}$ & $\begin{array}{l}\text { Karen Nicholson } \\
\text { Diana Soderbeck } \\
\text { Caroline Boaz }\end{array}$ \\
\hline April 15, 2016 & $\begin{array}{l}\text { Noon- } \\
\text { 4:30 p.m. }\end{array}$ & $\begin{array}{l}\text { "The circle is now complete" } \\
\text { Community and Diversity: Community Engagement, } \\
\text { Advancement, Diversiti Office, Gender Equity Center, Pride } \\
\text { Center, Cross-cultural Center, Veteran's Center }\end{array}$ & $\begin{array}{l}\text { Robert Carolin } \\
\text { Lourdes Shahamiri } \\
\text { Kambiz Hamadani } \\
\text { Talitha Matlin }\end{array}$ \\
\hline May 6, 2016 & $\begin{array}{l}\text { Noon- } \\
\text { 4:30 p.m. }\end{array}$ & “Remember....the force will be with you, always." & $\begin{array}{l}\text { Campus Connect } \\
\text { Director }\end{array}$ \\
\hline
\end{tabular}

April 22, 2016

"The circle is now complete"

\begin{tabular}{|c|c|c|c|}
\hline Time & Topic & Presenter & Location \\
\hline $12: 00 \mathrm{pm}$ & LUNCH & $\begin{array}{l}\text { Facilitators: } \\
\text { Lourdes Shahamiri, Kambiz Hamadani, } \\
\text { Talitha Matlin }\end{array}$ & Dome Patio \\
\hline $12: 45 \mathrm{pm}$ & \multicolumn{3}{|l|}{ Travel to Markstein Hall 202} \\
\hline 1:00 pm & Community Engagement & $\begin{array}{l}\text { Scott Gross } \\
\text { Associate Vice President, Community } \\
\text { Partnership Engagement } \\
\text { Sarah Villarreal } \\
\text { Associate Vice President, Community } \\
\text { Partnership Outreach }\end{array}$ & Markstein Hall 202 \\
\hline 1:30 pm & University Advancement & $\begin{array}{l}\text { Kyle Button } \\
\text { Associate Vice President, University } \\
\text { Advancement } \\
\text { Cathy Baur } \\
\text { Associate Vice President, Communications } \\
\text { Lori Brockett } \\
\text { Senior Director, Alumni Engagement \& } \\
\text { University Events }\end{array}$ & Markstein Hall 202 \\
\hline 2:00 pm & \multicolumn{3}{|c|}{ Break \& Travel to Cross Cultural Center } \\
\hline $2: 30 \mathrm{pm}$ & $\begin{array}{l}\text { Diversity, Educational Equity, } \\
\text { and Inclusion }\end{array}$ & $\begin{array}{l}\text { Patricia Prado-Olmos } \\
\text { Interim Chief Diversity Officer }\end{array}$ & $\begin{array}{l}\text { Cross Cultural } \\
\text { Center (USU 3400) }\end{array}$ \\
\hline $3: 00 \mathrm{pm}$ & $\begin{array}{l}\text { Pride Center \& Gender Equity } \\
\text { Center }\end{array}$ & $\begin{array}{l}\text { Abrahan Monzon } \\
\text { Assistant Director, ASI Community } \\
\text { Centers }\end{array}$ & $\begin{array}{l}\text { Gender Equity } \\
\text { Center } \\
\text { (USU } 3100 \text { \& 3200) }\end{array}$ \\
\hline $3: 30 \mathrm{pm}$ & $\begin{array}{l}\text { Cross Cultural Center \& } \\
\text { Multicultural programs }\end{array}$ & $\begin{array}{l}\text { Floyd Lai } \\
\text { Associate Director, Multicultural Programs }\end{array}$ & $\begin{array}{l}\text { Cross Cultural } \\
\text { Center (USU 3400) }\end{array}$ \\
\hline 4:00 pm & Debrief the Day & Jennifer Williams & $\begin{array}{l}\text { Cross Cultural } \\
\text { Center (USU } 3400 \text { ) }\end{array}$ \\
\hline 4:30 pm & Adjourn & & \\
\hline
\end{tabular}




\section{Campus Connect}

\section{Year 2 - Planning Campus Connect}

Participation in Campus Connect is a two-year commitment. During the first year of the program, participants will attend nine class sessions to learn more about the campus and the interconnected work being done to support the mission and strategic priorities of the university.

During the second year of the program, each member of the prior year's class will join one committee: selection, curriculum or orientation as well as facilitate one session of the

Campus Connect program for the incoming class.

Each committee serves a critical role in the success of the Campus Connect program. The charge for each committee is identified below:

- Selection Committee - the selection committee reviews applications and is charged with recommending a diverse group of individuals who will both benefit and contribute to the program. The selection committee's recommendation is due by June 1 st to ensure the new class is in finalized and notified by July $1^{\text {st. }}$.

- Curriculum Committee - the curriculum committee designs the upcoming year's curriculum to weave in the theme for the new class as well as showcase and highlight the various elements of CSUSM. The finalized curriculum is due by July $1^{\text {st. }}$

Please note: after the curriculum is finalized and using the information provided during the graduation session, the Campus Connect Director will create facilitation teams for each session.

- Orientation Committee - the orientation committee is responsible for creating a welcoming first experience for the new Campus Connect cohort, introducing the program and helping the new class get to know one another. This committee will facilitate the Orientation session in August.

The committee assignments will be confirmed and emailed out at the conclusion of the graduation ceremony.

Year two of the program also requires that each Campus Connect graduate facilitate one session. The facilitators, usually a group of 3 or 4 , are assigned in advance and are responsible for planning the day's activities, tours, and speakers/presentations. Room reservations and lunch menus will be handled by the Campus Connect Director. Session assignments will be sent out upon completion of the curriculum committee's work.

\section{Guidelines for Facilitators}

From a galaxy, far, far away... our staff and faculty want to be one with the force. This is why this year's theme "Campus Connect Awakens" is about developing the CSUSM force of leadership, consultation, and collaboration within the participants - a powerful leader of CSUSM culture they will become. We don't want Campus Connectors to go down a path where we can't follow. At the conclusion of Campus Connect, the possibility of successfully navigating CSUSM culture is 100\%. Because, henceforth; they will be known as Campus Connect Alums.

1) Establish skeletal draft agenda at least go days prior to the session. This should include recommending the lunch venue and location(s) for the session and should be submitted to the Campus Connect Director. Lunch
and snack will be arranged by Campus Connect staff. One thing's for sure, they're all going to be well fed.

2) Review the constructive feedback from the previous year's evaluations relative to each particular day's activities and to avoid "I have a bad feeling about this."

3) As applicable to your session, we encourage you to include one or more student presenters who will be able to provide a student perspective. You are also encouraged to use the life sized Star Wars cut-outs available provide a student
through the USU!

4) Create a schedule and plan for your session so that all topics are covered in the time allotted (Please be aware that Jennifer will dispense with the pleasantries. She will put you back on schedule). Contact presenters not less than 60 days in advance of the session date to gain consensus on presentation time allocations. Distribute the Guide for Presenters at this time.

5) When contacting presenters, inform them that incorporating "Campus Connect Awakens" theme is encouraged. Presenters should try to avoid lecture-style presentations, limit power points, and use interactive techniques in their presentations, such as:
- Q\&A sessions
- Videos
- Panel discussions

Student presenters

MAKE IT FUN ("Laugh it up, Fuzz Ball")!

6) Allow at least 45 minutes for lunch.

7) If a Campus Connect participant works in the department being discussed, include that individual in the program andlor de-brief. It is ageatway to buldconnections with their fellow classmates.

8) Final agenda is due to the Campus Connect Director 30 days prior to the class session

9) Distribute a final agenda with time allocations to all presenters at least 14 days prior to the session.

10) Ask that all presentations be sent to the facilitators 10 days prior to the session so that they can be compiled Ast one thumb drive.

11) Provide an introduction to the day at the beginning of each session.

12) Thank you cards will be sent to presenters by the Campus Connect staff to rejoice for their efforts to transform those into the force.

"Remember...the Force will be with you, always." 


\title{
EMPLOYEE ENGAGEMENT \& MARGINALIZED POPULATIONS: RESEARCH FINDINGS AND APPLICATIONS FOR PORTLAND STATE UNIVERSITY
}

\author{
BRENNA MIAIRA KUTCH \\ PORTLAND STATE UNIVERSITY \\ NOVEMBER 2017
}

